\title{
Investigating the consistency between proxy-based reconstructions and climate models using data assimilation: a mid-Holocene case study
}

\author{
A. Mairesse ${ }^{1}$, H. Goosse ${ }^{1}$, P. Mathiot ${ }^{2}$, H. Wanner $^{3}$, and S. Dubinkina ${ }^{1}$ \\ ${ }^{1}$ Université catholique de Louvain, Earth and Life Institute, Georges Lemaître Centre for Earth and Climate Research, \\ Place Louis Pasteur, 3, 1348 Louvain-la-Neuve, Belgium \\ ${ }^{2}$ British Antarctic Survey, Natural Environment Research Council, Cambridge, UK \\ ${ }^{3}$ Institute of Geography and Oeschger Centre for Climate Change Research, University of Bern, Bern, Switzerland \\ Correspondence to: A. Mairesse (aurelien.mairesse@uclouvain.be)
}

Received: 20 June 2013 - Published in Clim. Past Discuss.: 12 July 2013

Revised: 21 October 2013 - Accepted: 5 November 2013 - Published: 6 December 2013

\begin{abstract}
The mid-Holocene (6 kyr BP; thousand years before present) is a key period to study the consistency between model results and proxy-based reconstruction data as it corresponds to a standard test for models and a reasonable number of proxy-based records is available. Taking advantage of this relatively large amount of information, we have compared a compilation of 50 air and sea surface temperature reconstructions with the results of three simulations performed with general circulation models and one carried out with LOVECLIM, a model of intermediate complexity. The conclusions derived from this analysis confirm that models and data agree on the large-scale spatial pattern but the models underestimate the magnitude of some observed changes and that large discrepancies are observed at the local scale. To further investigate the origin of those inconsistencies, we have constrained LOVECLIM to follow the signal recorded by the proxies selected in the compilation using a data-assimilation method based on a particle filter. In one simulation, all the 50 proxy-based records are used while in the other two only the continental or oceanic proxy-based records constrain the model results. As expected, data assimilation leads to improving the consistency between model results and the reconstructions. In particular, this is achieved in a robust way in all the experiments through a strengthening of the westerlies at midlatitude that warms up northern Europe. Furthermore, the comparison of the LOVECLIM simulations with and without data assimilation has also objectively identified 16 proxybased paleoclimate records whose reconstructed signal is ei-
\end{abstract}

ther incompatible with the signal recorded by some other proxy-based records or with model physics.

\section{Introduction}

The Holocene, our current interglacial, has been the subject of a large number of studies based on reconstructions derived from proxy records (e.g., Bartlein et al., 2011; Davis et al., 2003; Leduc et al., 2010; Marcott et al., 2013; Viau and Gajewski, 2009; Vinther et al., 2009) and on simulations performed with climate models of various complexities (e.g., Braconnot et al., 2007a,b; Claussen et al., 1999; Crucifix, 2008; Renssen et al., 2012; Zhao et al., 2005). The two approaches are complementary (Mock, 2007) as the information inferred from the proxies often serves to validate the climate model results (Braconnot et al., 2012) while the models allow the exploration of the physical processes responsible for the recorded climatic changes.

In particular, the mid-Holocene, corresponding to $6 \mathrm{kyr}$ BP (thousand years before present), is a standard period in the Paleoclimate Modelling Intercomparison Project (PMIP) for which boundary conditions have been specified to facilitate the comparison between model results and proxybased reconstructions (hereafter often referred to as reconstructions, for simplicity). One of the most robust conclusions of those model studies is that the summer of the mid to high latitudes of the Northern Hemisphere is warmer during 
the mid-Holocene compared to the pre-industrial conditions (Braconnot et al., 2007a). This is consistent with the trends of the regional pollen-based reconstructions of Bartlein et al. (2011) and Davis et al. (2003) for northern Europe and with several other proxy-based records (e.g., Andreev et al., 2003; Clegg et al., 2010; Marcott et al., 2013; Seppä and Birks, 2002, 2001; Vinther et al., 2009).

The model-data comparisons have nonetheless underlined some major differences between reconstructions and simulation results. Brewer et al. (2007b) have highlighted that PMIP2 models are able to capture the large-scale surface temperature patterns over Europe reconstructed from pollen records, but they tend to underestimate the magnitude of the observed changes, which is also in agreement with the conclusion of Braconnot et al. (2007a). Previous studies (e.g., Lohmann et al., 2013; Lorenz et al., 2006; Schneider et al., 2010) have found similar results when analyzing the trends of the Holocene sea surface temperature obtained mainly from alkenone data: data and models are in relatively good agreement regarding the sign of the trend while the models underestimate the magnitude of the changes. Furthermore, Hargreaves et al. (2013) have shown that, at the local scale, models fail to reproduce the difference between mid-Holocene and pre-industrial temperature reconstructed by Leduc et al. (2010) for sea surface temperature and Bartlein et al. (2011) for land temperature.

Our goal here is to further investigate the origin of those inconstancies between model results and reconstructions using simulations with data assimilation. Data assimilation evaluates which state of the system is the most consistent with all the sources of information, derived here from a climate model, the forcing and the proxy-based records. By performing different experiments, driven by different subsets of proxy-based records, we plan to identify the ones that are compatible with model physics, the ones that are not, and those that are incompatible with other proxy-based reconstructions.

We focus on the mid-Holocene as this is a welldocumented period. LOVECLIM1.2 (Goosse et al., 2010), a three-dimensional Earth model of intermediate complexity, is constrained to follow a compilation of 50 air and sea surface temperature reconstructions located in the Northern Hemisphere by means of a particle filter with resampling (Dubinkina et al., 2011). These simulations with data assimilation will be compared with a simulation performed with LOVECLIM without data assimilation and with three GCM (general circulation model) simulations following the PMIP3-CMIP5 framework (Paleoclimate Models Intercomparison Project phase 3 - Coupled Model Inter-comparison Project phase 5) in order to assess the dependance of modeldata differences on the model selected.

\section{Methodology}

\subsection{Description of LOVECLIM1.2}

LOVECLIM1.2 is based on a simplified representation of the dynamics of the climate system and has a coarse horizontal and vertical resolution that enables low computational requirements. Therefore, the large ensembles of simulations required by data assimilation can be performed at a reasonable cost. This model includes three main components named ECBilt2, CLIO3 and VECODE, which represent the development of the atmosphere, the ocean and the vegetation, respectively. ECBilt2 is a spectral T21 (corresponding to about $5.625^{\circ}$ in latitude and longitude) global three-level quasi-geostrophic model (Opsteegh et al., 1998). CLIO3 is an ocean general circulation model coupled to a comprehensive sea ice model (Goosse and Fichefet, 1999). It has a horizontal resolution of $3^{\circ} \times 3^{\circ}$ and 20 unequally spaced vertical levels ranging from $10 \mathrm{~m}$ near surface to $500 \mathrm{~m}$ at $5500 \mathrm{~m}$ depth. VECODE is the continental biosphere component that describes the distribution of trees, grass and desert at the same resolution as ECBilt2 (Brovkin et al., 1997). For a complete description of LOVECLIM1.2 please refer to Goosse et al. (2010).

\subsection{Data-assimilation method}

The results of a simulation performed with a climate model depend on (i) the physics of the climate model, (ii) the initial conditions used to initialize the simulation and (iii) the forcing used to drive the model such as, for instance, the amount of solar radiation received by Earth. Here, in order to obtain an ensemble of simulations that represents possible mid-Holocene climate states, we change only the initial conditions by adding a small noise to the sea surface temperature, while the physics and the forcing are kept unchanged.

Due to the chaotic nature of the climate system, even small perturbations in initial conditions result in trajectories that quickly deviate from each other. These different trajectories are called particles or ensemble members. Starting from different initial conditions and using the LOVECLIM climate model, we propagate 96 particles forward in time for an interval of six months: from December until May and then from July until November, thus with a restart each 1 December and 1 July. This is repeated during $400 \mathrm{yr}$. The interval of six months (the assimilation frequency) has been chosen to follow more precisely the seasonal signal embedded in reconstructions as more than $60 \%$ of the selected proxy-based records represent a month or a particular season (mainly winter and summer, the coldest or the hottest month). The amount of 96 particles has been chosen because it provides a satisfactory climate range at an affordable computing cost (Dubinkina et al., 2011; Goosse et al., 2006).

After the propagation step and before another restart, the 96 climate states are evaluated according to their agreement 
Table 1. Air surface (TS) and sea surface (SST) mid-Holocene temperature proxy-based reconstructions used in the simulations with data assimilation. Winter corresponds to December-February (DJF) and summer to June-August (JJA). The anomalies and their error are in ${ }^{\circ} \mathrm{C}$.

\begin{tabular}{|c|c|c|c|c|c|c|c|c|c|c|}
\hline ID & Lat & Lon & Site or core name & Area & Archive type & $\begin{array}{c}\text { Proxy-based } \\
\text { reconstruction }\end{array}$ & $\begin{array}{l}\text { Temporal } \\
\text { interpretation }\end{array}$ & $\begin{array}{r}6 \mathrm{kyr} \\
\mathrm{BP} \text { ano. }\end{array}$ & Error & Reference \\
\hline 1 & 61.48 & 26.07 & Laihalampi Lake & Southern Finland & Pollen & TS & Annual & 1.86 & 0.60 & Heikkilä and Seppä (2003) \\
\hline 2 & 69.20 & 21.47 & Toskaljavri Lake & Northern Finland & Pollen & TS & Jul & 1.06 & 0.60 & Seppä and Birks (2002) \\
\hline 2 , & 68.68 & 22.08 & Tsuolbmajavri Lake & Northern Finland & Pollen & TS & Jul & 1.14 & 0.60 & Seppä and Birks (2001) \\
\hline 3 & 55.65 & -13.98 & Feni Drift & North Atlantic & Alkenone - $\mathrm{U}_{k}^{37}$ & SST & Annual & 0.47 & 0.80 & Esparza (2005) \\
\hline 4 & 40.50 & 4.03 & Minorca & Mediterranean & Alkenone $-\mathrm{U}_{k}^{37}$ & SST & Annual & 2.38 & 0.80 & Martrat (2007) \\
\hline 5 & 43.88 & -62.80 & OCE326-GGC30 & Northwest Atlantic & Alkenone $-\mathrm{U}_{k}^{37}$ & SST & Annual & 4.15 & 0.80 & Sachs (2007) \\
\hline 6 & 43.48 & -54.87 & OCE326-GGC26 & Northwest Atlantic & Alkenone - $\mathrm{U}_{k}^{37}$ & SST & Annual & 2.81 & 0.80 & Sachs (2007) \\
\hline 7 & 37.56 & -10.14 & MD01-2444 & Iberian Margin & Alkenone $-\mathrm{U}_{k}^{37}$ & SST & Annual & 0.63 & 0.80 & Martrat et al. (2007) \\
\hline 8 & 66.60 & -17.58 & JR51-GC35 & Nordic Seas & Alkenone $-\mathrm{U}_{k}^{37}$ & SST & Annual & -1.10 & 0.80 & Bendle and Rosell-Melé (2007) \\
\hline 9 & 30.85 & -10.27 & GeoB 6007-02 & Northwest Africa & Alkenone $-\mathrm{U}_{k}^{37}$ & SST & Annual & 1.02 & 0.80 & Kim et al. (2007) \\
\hline 10 & 38.63 & -9.45 & D13882 & Iberian Margin & Alkenone - $\mathrm{U}_{k}^{37}$ & SST & Annual & 2.27 & 0.80 & Rodrigues et al. (2009) \\
\hline 11 & 62.09 & -17.82 & RAPiD-12-1k & Sub-polar North Atlantic & $\begin{array}{l}\mathrm{Mg} / \mathrm{Ca} \text { and } \delta^{18} \mathrm{O} \\
\text { (bulloides) }\end{array}$ & SST & May, Jun & -1.12 & 0.80 & Thornalley et al. (2009) \\
\hline 12 & 60.08 & 15.83 & Stora Gilltjarnen & Sweden & Pollen & TS & Annual & 1.01 & 0.60 & Antonsson et al. (2006) \\
\hline 13 & 60.58 & 24.08 & Lake Arapisto & Finland & Pollen & TS & Annual & 3.04 & 0.60 & Sarmaja-Korjonen and Seppä (2007) \\
\hline 14 & 58.55 & 13.67 & Lake Flarken & Sweden & Pollen & TS & Annual & 2.04 & 0.60 & Seppä et al. (2005) \\
\hline 15 & 66.97 & 7.63 & $\begin{array}{l}\text { JM97-948/2A and } \\
\text { MD95-2011 }\end{array}$ & Norwegian Sea & Forams (planktic) & SST & Aug & -1.77 & 0.80 & Risebrobakken et al. (2003) \\
\hline 16 & 74.47 & 98.63 & Levinson-Lessing Lake & Russia & Pollen & TS & Annual & 2.06 & 0.60 & Andreev et al. (2003) \\
\hline 17 & 41.68 & -124.93 & ODP1019C & North Pacific & Alkenone $-\mathrm{U}_{k}^{37}$ & SST & Annual & -0.84 & 0.80 & Barron et al. (2003) \\
\hline 18 & 20.75 & -18.58 & ODP658C & Northwest Africa sea & Forams (planktic) & SST & Aug & -3.05 & 0.80 & deMenocal et al. (2000) \\
\hline 19 & 20.75 & -18.58 & ODP658C & Northwest Africa sea & Forams (planktic) & SST & $\mathrm{Feb}$ & -1.07 & 0.80 & deMenocal et al. (2000) \\
\hline 20 & 31.48 & 128.52 & Core B-3GC & Northwestern Pacific Ocean & Forams (planktic) & SST & Summer & -0.54 & 0.80 & Jian et al. (2000) \\
\hline 21 & 31.48 & 128.52 & Core B-3GC & Northwestern Pacific Ocean & Forams (planktic) & SST & Winter & -1.59 & 0.80 & Jian et al. (2000) \\
\hline 22 & 66.55 & 13.92 & SG93 & Norway (Soylegrotta) & Speleothem & TS & Annual & -0.19 & 0.80 & Lauritzen and Lundberg (1999) \\
\hline 23 & 58.58 & 26.65 & Raigastvere Lake & Estonia & Pollen & TS & Annual & 2.63 & 0.60 & Seppä and Poska (2004) \\
\hline 24 & 36.03 & 141.78 & $\begin{array}{l}\text { KR02-06 St.A MC/GC } \\
\text { and MD01-2421 }\end{array}$ & Northwestern Pacific & Alkenone - $\mathrm{U}_{k}^{37}$ & SST & Summer & 2.08 & 0.80 & Isono et al. (2009) \\
\hline 25 & 20.12 & 117.38 & GIK17940-2 & South China Sea & Alkenone - $\mathrm{U}_{k}^{37}$ & SST & Annual & -0.19 & 0.80 & Pelejero et al. (1999) \\
\hline 26 & 52.78 & 108.12 & Kotokel Lake & Russia & Pollen & TS & Jan & 3.30 & 0.60 & Tarasov et al. (2009) \\
\hline 27 & 52.78 & 108.12 & Kotokel Lake & Russia & Pollen & TS & Jul & -0.07 & 0.60 & Tarasov et al. (2009) \\
\hline 28 & 80.70 & -73.70 & Agassiz Ice Cap & Greenland & ice core $-\delta^{18} \mathrm{O}$ & TS & Annual & 2.00 & 0.40 & Vinther et al. (2009) \\
\hline 29 & 71.27 & -26.73 & Renland Ice Cap & Greenland & ice core $-\delta^{18} \mathrm{O}$ & TS & Annual & 2.00 & 0.40 & Vinther et al. (2009) \\
\hline 30 & 50 to 70 & -65 to -50 & Labrador region & Canada & Pollen & TS & Jan & -2.28 & 0.60 & Viau and Gajewski (2009) \\
\hline 31 & 50 to 70 & -65 to -50 & Labrador region & Canada & Pollen & TS & Jul & -0.48 & 0.60 & Viau and Gajewski (2009) \\
\hline 32 & 50 to 70 & -120 to -80 & Central Canada region & Canada & Pollen & TS & Jan & 0.68 & 0.60 & Viau and Gajewski (2009) \\
\hline 33 & 50 to 70 & -120 to -80 & Central Canada region & Canada & Pollen & TS & Jul & 0.49 & 0.60 & Viau and Gajewski (2009) \\
\hline 34 & 50 to 70 & -140 to -120 & Mackenzie region & Canada & Pollen & TS & Jan & 0.46 & 0.60 & Viau and Gajewski (2009) \\
\hline 35 & 50 to 70 & -140 to -120 & Mackenzie region & Canada & Pollen & TS & Jul & 0.17 & 0.60 & Viau and Gajewski (2009) \\
\hline 36 & 44.53 & 145.00 & MD01-2412 & Okhotsk Sea & Alkenone - $\mathrm{U}_{k}^{37}$ & SST & Autumn & -0.82 & 0.80 & Harada et al. (2006) \\
\hline 37 & 71.34 & -113.78 & KR02 lake & Victoria Island (Canada) & Pollen & TS & Jul & 0.00 & 0.60 & Peros and Gajewski (2008) \\
\hline 38 & 55 to 72 & -12 to 15 & Northwest region & Europe & Pollen & TS & Winter & -0.71 & 0.60 & Davis et al. (2003) \\
\hline 39 & 55 to 72 & -12 to 15 & Northwest region & Europe & Pollen & TS & Summer & 1.00 & 0.60 & Davis et al. (2003) \\
\hline 40 & 45 to 55 & -12 to 15 & Central-west region & Europe & Pollen & TS & Winter & -0.51 & 0.60 & Davis et al. (2003) \\
\hline 41 & 45 to 55 & -12 to 15 & Central-west region & Europe & Pollen & TS & Summer & 0.47 & 0.60 & Davis et al. (2003) \\
\hline 42 & 30 to 45 & -12 to 15 & Southwest region & Europe & Pollen & TS & Winter & -0.98 & 0.60 & Davis et al. (2003) \\
\hline 43 & 30 to 45 & -12 to 15 & Southwest region & Europe & Pollen & TS & Summer & -1.49 & 0.60 & Davis et al. (2003) \\
\hline 44 & 55 to 72 & 15 to 50 & Northeast region & Europe & Pollen & TS & Winter & 0.22 & 0.60 & Davis et al. (2003) \\
\hline 45 & 55 to 72 & 15 to 50 & Northeast region & Europe & Pollen & TS & Summer & 0.60 & 0.60 & Davis et al. (2003) \\
\hline 46 & 45 to 55 & 15 to 50 & Central-east region & Europe & Pollen & TS & Winter & 0.24 & 0.60 & Davis et al. (2003) \\
\hline 47 & 45 to 55 & 15 to 50 & Central-east region & Europe & Pollen & TS & Summer & -0.11 & 0.60 & Davis et al. (2003) \\
\hline 48 & 30 to 45 & 15 to 50 & Southeast region & Europe & Pollen & TS & Winter & -0.25 & 0.60 & Davis et al. (2003) \\
\hline 49 & 30 to 45 & 15 to 50 & Southeast region & Europe & Pollen & TS & Summer & -0.66 & 0.60 & Davis et al. (2003) \\
\hline
\end{tabular}

with the air and the sea surface temperature reconstructions inferred from the proxies. This evaluation is derived from the comparison of a likelihood of each particle estimated as a function of the difference between the climate state of the particle and the proxy-based reconstructions. It is based on the surface air and sea surface temperature anomalies obtained from both the model and proxy-based reconstruction as the difference between mid-Holocene (the period $6 \pm 0.5 \mathrm{kyr} \mathrm{BP}$ ) and modern conditions (the period 950$450 \mathrm{yr} \mathrm{BP})$. This difference is computed for all the locations and months for which proxy-based reconstructions are available (Table 1). For instance, during a "winter" step of data assimilation (when the model is propagated from December until May), one of the proxy-based reconstructions that is taken into account in the computation of the likelihood is the reconstruction number 21 (hereafter N21) for which its mean winter anomaly value is compared to the anomaly of the winter (December-February) sea surface temperature of the corresponding LOVECLIM grid point while the proxybased reconstruction $\mathrm{N} 20$ is not taken into account at this step because it represents a summer anomaly. As the methodology does not allow taking into account different time resolutions (Mathiot et al., 2013), the annual proxy-based reconstructions are compared to model values twice a year: to the mean value of December-May during a "winter" step of assimilation, and to the mean value of June-November during a "summer" step of assimilation (when the model is propagated from July until November).

The particles that have highest likelihood are retained while the particles with small likelihood are eliminated. The remaining particles are resampled a number of times proportional to their likelihood so that the total number of particles 
is kept constant. This resampling step is necessary to avoid a collapse of an ensemble of particles to one single particle. Then, a small perturbation of the surface temperature is added to the initial conditions of the ensemble members and the particles are propagated forward in time for the next 6 months of assimilation using the climate model. For more details about the methodology, which has been applied in several recent studies (e.g., Goosse et al., 2012; Mathiot et al., 2013), please refer to Dubinkina et al. (2011).

\subsection{The proxy-based data set}

Numerous surface and sea surface temperature reconstructions derived from proxies are available for the Holocene. These reconstructions are derived from marine, continental and ice archives using different methods such as, among others, the alkenone paleothermometry (Grimalt and Lopez, 2007; Herbert, 2003), the modern analog technique (Brewer et al., 2007a) or the stable isotopes analysis (Brook, 2007). Each quantitative reconstruction has its strengths and weaknesses (Birks et al., 2010; Juggins, 2013; Telford and Birks, 2005). For instance, almost all of them are influenced by the confounding effects, which means that environmental variables other than the climate variable of interest influence the reconstruction (Birks et al., 2010; Ortiz, 2007). For instance, a summer temperature derived from pollen records could include a signal related to winter temperature or precipitation (Birks et al., 2010). Furthermore, attributing the signal to a particular period of the year is not always straightforward as, for instance, the sedimentary alkenone signal is usually assumed to reflect the annually averaged sea surface temperature while at high latitudes the alkenone signal is likely phased to the summer months (Bendle and RosellMelé, 2007; Herbert, 2003; Samtleben and Bickert, 1990; Thomsen et al., 1998). In this study, we decided to follow the interpretation proposed in the original studies describing the proxy-based reconstructions. For instance, if the reconstructed signal represents the summer surface air temperature according to the authors of those studies, this is also the case for us.

Our goal is not to include all the available local proxybased reconstructions. When a choice has to be made, we prefer to use regional-scale reconstructions such as the ones of Davis et al. (2003) and Viau and Gajewski (2009) rather than the individual records that were included in those reconstructions.

The proxy-based reconstructions data set used in the simulations with data assimilation results then from a selection among more than 300 Holocene records according to the following criteria: (i) the record represents the air or the sea surface temperature, (ii) comes from archives located between 20 and $90^{\circ} \mathrm{N}$, (iii) covers the full mid-Holocene time-slice $(6 \pm 0.5 \mathrm{kyr} \mathrm{BP})$ and the reference period $(950-450 \mathrm{yr} \mathrm{BP})$ with a resolution of at least $250 \mathrm{yr}$, as we work with anomalies related to this period (Sect. 2.2). (iv) If multiple recon- structions with different temporal interpretations are located within the same model grid, the seasonal reconstructions are retained, as we consider that it provides more information on the system. On the basis of these criteria, we have selected 50 proxy-based records of air and sea surface temperature for the mid-Holocene (Table 1). For each selected record, an anomaly is calculated between the mean value of the period of interest $(6 \pm 0.5 \mathrm{kyr} \mathrm{BP})$ and the mean value of the reference period (950-450 yr BP) (Fig. 1). As we perform averages over periods that are longer than the dating uncertainties of the records, we neglect any potential biases related to those dating uncertainties.

Furthermore, if two reconstructions that represent the same physical variable at the same period of the year are located in the same model grid, they are averaged. This is the case for the proxy-based reconstruction $\mathrm{N} 2$ and $\mathrm{N} 2$, which are merged under the identifier N2. In the evaluation of the likelihood, we assume that a proxy-based reconstruction represents the climate of the scale of the model grid, except for the reconstructions of Davis et al. (2003) and Viau and Gajewski (2009), which explicitly refer to a larger scale and, therefore, the average over the corresponding region for the model is performed before computing the model-data difference. Therefore, the signal reconstructed from the proxies is representative on a $3^{\circ}$ grid box for $\mathrm{CLIO} 3$ and a $5.625^{\circ}$ grid box for ECBilt2.

Finally, an estimation of the uncertainty for each reconstruction derived from proxy is required for data assimilation. This information is frequently not available, and when it is, these uncertainties are often very large and thus sometimes of the same order as the signal itself (Ohlwein and Wahl, 2011). As in Mathiot et al. (2013), we have thus deliberately selected here lower bounds for those uncertainties in order to provide a strong constraint on the model during the data-assimilation process. By simplicity, we have also chosen only one error for each archive type (Table 1) based on values provided in previous studies (e.g., Heikkilä and Seppä, 2003; Martrat et al., 2007; Mathiot et al., 2013; Müller et al., 1998; Seppä and Birks, 2001). Those uncertainty values affect weakly the spatial patterns but influence the magnitude of the changes induced by the data assimilation processes (Goosse et al., 2012). This will be taken into account in the interpretation of our results.

\subsection{Experimental design}

Three mid-Holocene simulations with data assimilation are performed and compared to a mid-Holocene reference simulation realized with LOVECLIM, named NODATA (Table 2). In two simulations either the continental or the oceanic proxy-based reconstructions are assimilated and in one simulation these proxy-based reconstructions are assimilated together. They are named CON, OCE and ALL, respectively. The objective is to propose two extreme cases in which we either constrain the model by only the continental 


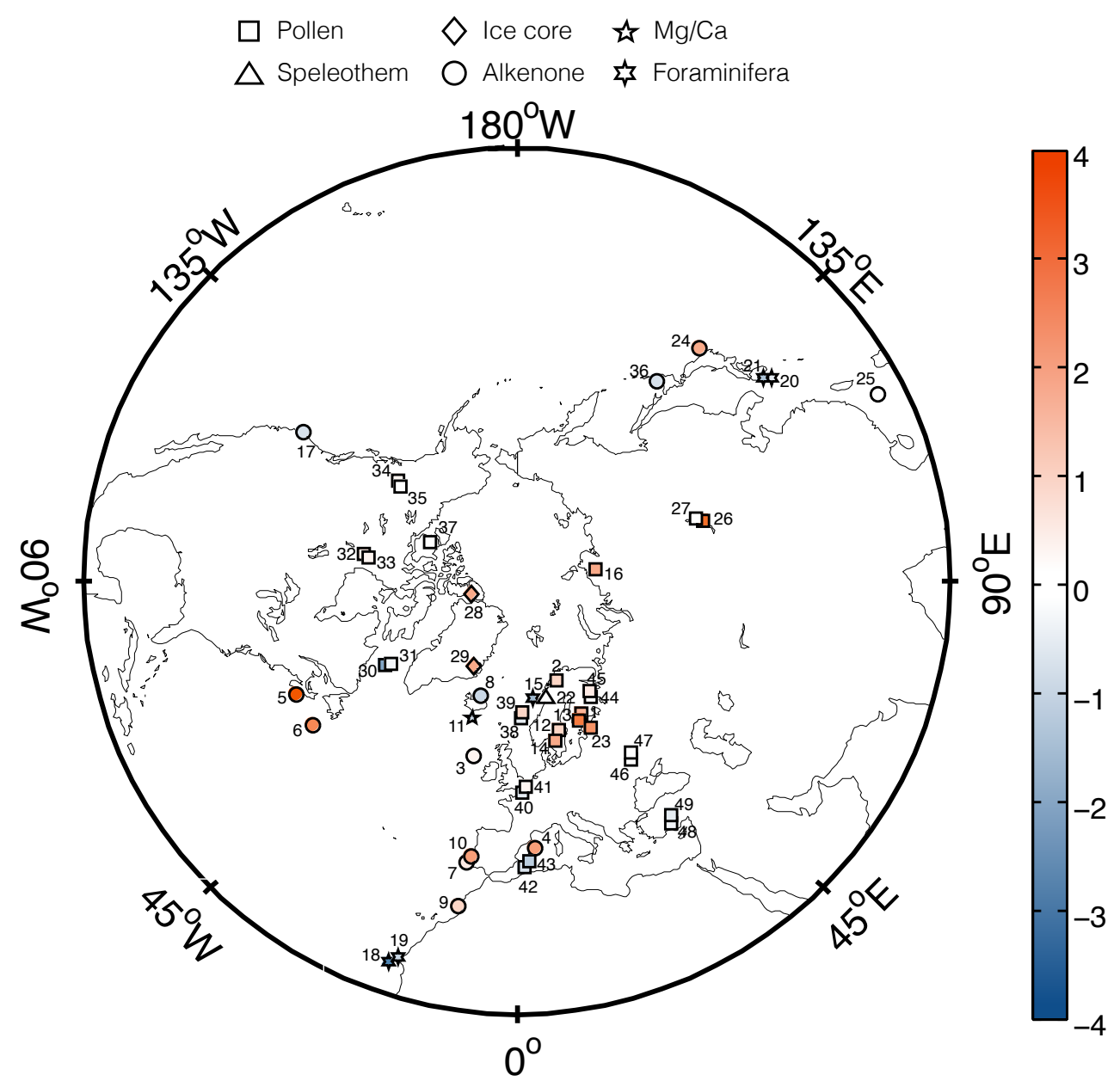

Fig. 1. Mean air and sea surface temperature anomaly $\left({ }^{\circ} \mathrm{C}\right)$ for all the proxy-based reconstructions selected for the mid-Holocene. Each marker type corresponds to a different proxy-based reconstruction group. Each anomaly represents a month or a particular period (Table 1). If more than one proxy-based reconstruction is given at the same location, the markers representing the proxy-based reconstructions are slightly shifted for improved readability. The reference period is $950-450 \mathrm{yr} \mathrm{BP}$.

reconstructions or by only the signal inferred from oceanic ones in order to identify the information brought by each subset as well as the compatibility between model physics and the proxy-based reconstructions, and between the proxybased reconstructions themselves. In addition, a simulation spanning the reference period $(950-450 \mathrm{yr} \mathrm{BP})$ is required as the likelihood in the data-assimilation process compares proxy-based reconstruction anomalies with modeled anomalies (Sect. 2.2). This simulation is driven by both natural and anthropogenic forcings as in Crespin et al. (2013).

We also analyze simulations performed with GCMs to allow the comparison of the LOVECLIM results with the ones from three state-of-the-art models: BCC-CSM1-1, CSIROMk3L-1-2 and MPI-ESM-P. For details about these models, please refer to the references listed in Table 2. These models were chosen because at the time of our analysis they were the only ones on the CMIP5 data portal that provide the variables needed for our diagnostics over the period $950-450 \mathrm{yr}$ BP and the mid-Holocene.

The four mid-Holocene simulations performed with LOVECLIM are either 200 (NODATA) or $400 \mathrm{yr}$ long (ALL, CON and OCE). The length of the simulation NODATA is smaller because it is the prolongation of an equilibrium simulation in the same conditions. The four simulations are driven by the same constant forcing as done in Mathiot et al. (2013). The orbital parameters follow Berger (1978). The greenhouse gas concentrations are based on the data of Flückiger et al. (2002). The Laurentide Ice Sheet topography and surface albedo have been adapted for LOVECLIM by Renssen et al. (2009) from the reconstruction of Peltier (2004). In comparison to the present, the changes in topography and surface albedo are extremely small. As in Mathiot et al. (2013) small fresh water fluxes $(26 \mathrm{mSv})$ coming from the Antarctic Ice Sheet are added in the Amundsen, the Bellingshausen and the west part of Weddell Sea, based on Pollard 
Table 2. List of the simulations analyzed in this study.

\begin{tabular}{|c|c|c|c|c|c|}
\hline $\begin{array}{l}\text { Model } \\
\text { name }\end{array}$ & $\begin{array}{l}\text { Simulation } \\
\text { period }\end{array}$ & $\begin{array}{l}\text { Simulation } \\
\text { name }\end{array}$ & Forcing & $\begin{array}{l}\text { Data } \\
\text { assimilation }\end{array}$ & Reference \\
\hline \multirow{5}{*}{ LOVECLIM } & reference & LMALL & Crespin et al. (2013) & no & \multirow{5}{*}{ Goosse et al. (2010) } \\
\hline & mid-Holocene & ALL & this study & yes & \\
\hline & mid-Holocene & $\mathrm{CON}$ & this study & yes & \\
\hline & mid-Holocene & OCE & this study & yes & \\
\hline & mid-Holocene & NODATA & this study & no & \\
\hline \multirow{2}{*}{ MPI-ESM-P } & reference & past 1000 & PMIP3 & no & \multirow{2}{*}{$\begin{array}{l}\text { Raddatz et al. (2007); } \\
\text { Marsland et al. (2003) }\end{array}$} \\
\hline & mid-Holocene & mid-Holocene & PMIP3 & no & \\
\hline \multirow{2}{*}{ CSIRO-Mk3L-1-2 } & reference & past 1000 & PMIP3 & no & \multirow{2}{*}{ Phipps et al. (2011) } \\
\hline & mid-Holocene & mid-Holocene & PMIP3 & no & \\
\hline \multirow{2}{*}{ BCC-CSM1-1 } & reference & past 1000 & PMIP3 & no & \multirow{2}{*}{$\begin{array}{l}\text { http://bcc.cma.gov.cn/bccsm/ } \\
\text { web/?ChannelID=43 }\end{array}$} \\
\hline & mid-Holocene & mid-Holocene & PMIP3 & no & \\
\hline
\end{tabular}

and DeConto (2009). For the Northern Hemisphere, there are no fresh water fluxes resulting from the melt of the Laurentide Ice Sheet for this period (as in Renssen et al., 2009). This design is slightly different from the PMIP3 protocol used in GCMs as the latter assumed a similar ice sheet topography as the present one and no additional freshwater fluxes from ice sheet melting. But this has only a very marginal effect on our results at $6 \mathrm{kyr} \mathrm{BP}$.

\section{Results and discussion}

\subsection{Simulations without data assimilation}

The climate anomalies simulated by LOVECLIM and the selected GCMs for mid-Holocene conditions display similar large-scale patterns (Fig. 2) and are consistent with previous modeling studies (e.g., Braconnot et al., 2007a). They all depict warmer air and sea surface temperature during the mid-Holocene summer and cooler air surface temperature during the winter, except in the Arctic. The mid-Holocene seasonal cycle amplitude is then more pronounced than the one of the reference period for most of the locations in the Northern Hemisphere. This signal is mainly caused by the higher (lower) summer (winter) insolation for mid-Holocene (Braconnot et al., 2007a; Wanner et al., 2008). The winter Arctic warming is due to a memory effect associated with the summer insolation as the latter induces a decrease in ice thickness, which leads to larger oceanic heat fluxes during the autumn and the winter, and then to a surface temperature increase during these seasons (Renssen et al., 2005).

In comparison with the first half of the last millennium, the westerlies are slightly weakened during the mid-Holocene in LOVECLIM during winter (Fig. 3). This appears consistent with a smaller meridional gradient in temperature due to the Arctic warming and leads to a tendency towards a more negative NAO state in the model for that period. BCC-CSM1-1 also shows a weakening of the westerlies in the Pacific during the mid-Holocene while MPI-ESM-P and CSIRO-Mk3L-1-2 show a slight strengthening. These results are consistent with an analysis of PMIP2 simulations realized by Gladstone et al. (2005) showing that many models display anomalies similar to either positive or negative NAO phases during the midHolocene compared to present day but without a clear and robust signal common between the different models.

The mid-Holocene reconstruction based on proxies (Fig. 2) depicts a less homogeneous pattern than the modeled one. The Arctic and northern Europe surface air temperatures are warmer during the summer and the winter, which is in agreement with model results, while the Norwegian sea surface temperature is colder in the selected proxy-based reconstruction for the same seasons, in contrast to model results. Risebrobakken et al. (2003) argue that this reconstructed cooling in the Norwegian Sea may rather represent a subsurface signal, explaining the discrepancy with other estimates of surface temperature in the region. Over Europe, the northern part is warmer during the mid-Holocene and the southern one is colder all year long in the proxy-based reconstructions. Those changes are relatively consistent with the simulation results in winter, although the signal at high latitudes appears underestimated in many models, but no model is able to reproduce a cooling in summer over southern Europe. In the western North Atlantic, reconstructed sea surface temperature is warmer, which is consistent in summer but not with the winter signal simulated by LOVECLIM and BCCCSM1-1. In North America, surface temperature is slightly warmer in the reconstructions over the western part while it is colder over the eastern part, a signal that appears thus weaker than the one simulated by models.

A more quantitative model-data comparison shows that the magnitude of the signal (estimated here by the standard deviation of the anomalies) is much weaker in models, with a mean value of $0.9^{\circ} \mathrm{C}$, than in reconstructions based on 


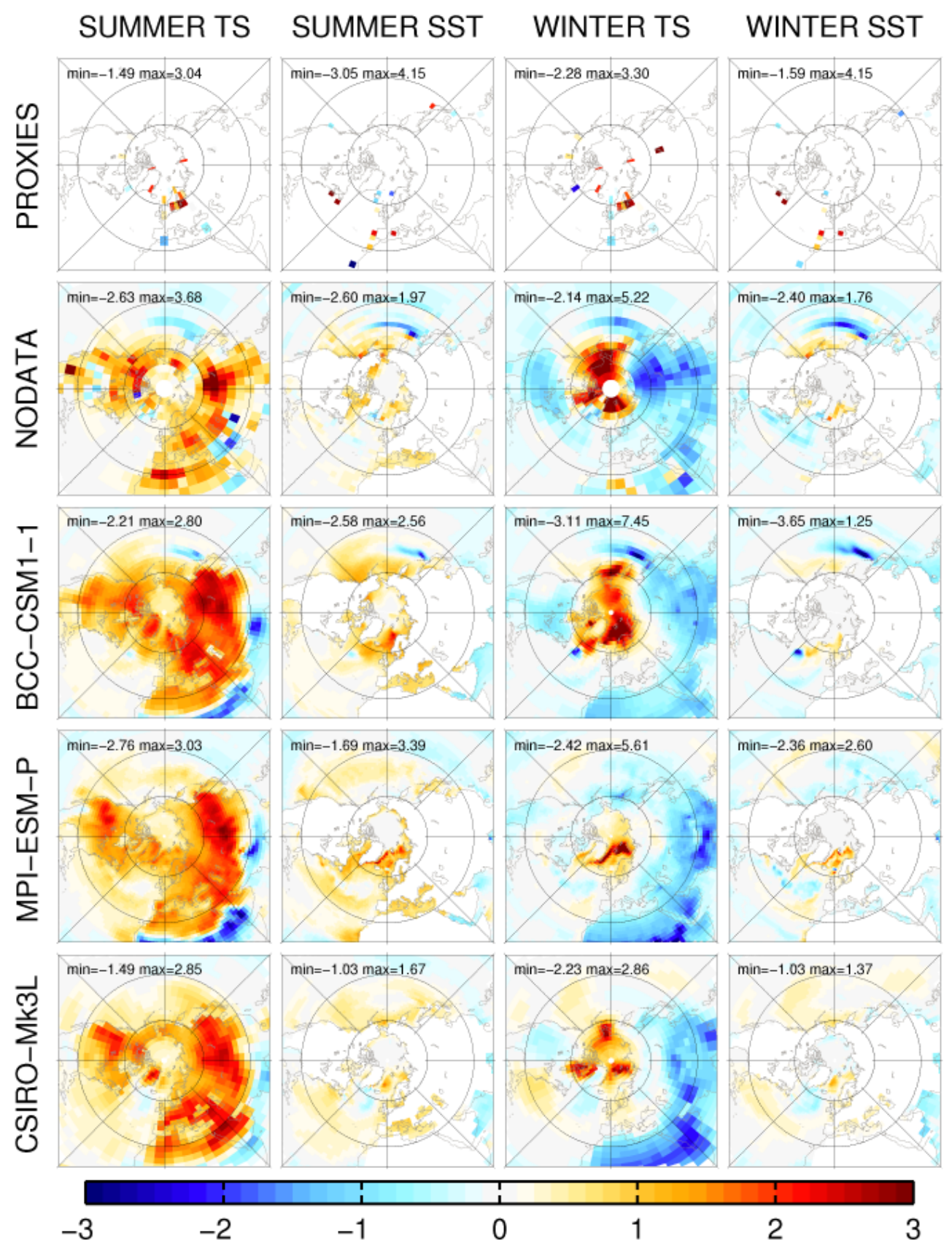

Fig. 2. Mid-Holocene air (TS) and sea (SST) surface temperature anomaly $\left({ }^{\circ} \mathrm{C}\right)$ for the proxy-based reconstructions, LOVECLIM without data assimilation (NODATA) and the GCMs. Winter corresponds to December-February (DJF) and summer to June-August (JJA). The reference period is $950-450 \mathrm{yr} \mathrm{BP}$.

proxies, which reach a value of $1.6^{\circ} \mathrm{C}$ (Fig. 4). The difference is seen both for continental and oceanic proxy-based reconstructions but is more marked over the ocean where the signal in the proxy-based reconstructions is 4.5 times greater than one of models, a result consistent with the recent findings of Lohmann et al. (2013). According to Fig. 4, the mean signal recorded by the selected proxies is larger over the ocean that over land by about $0.5^{\circ} \mathrm{C}$. This might ap- pear surprising as the oceanic response to many forcings is expected to be smaller than the one over continents because of the larger thermal inertia of the ocean and of various feedbacks (e.g., Boer, 2011; Joshi et al., 2013). Investigating this issue in detail is out of the scope of this study, but it might be related to the too small number of proxy-based reconstructions used here to estimate precisely the mean over oceans and continents or to the location of oceanic proxy-based 


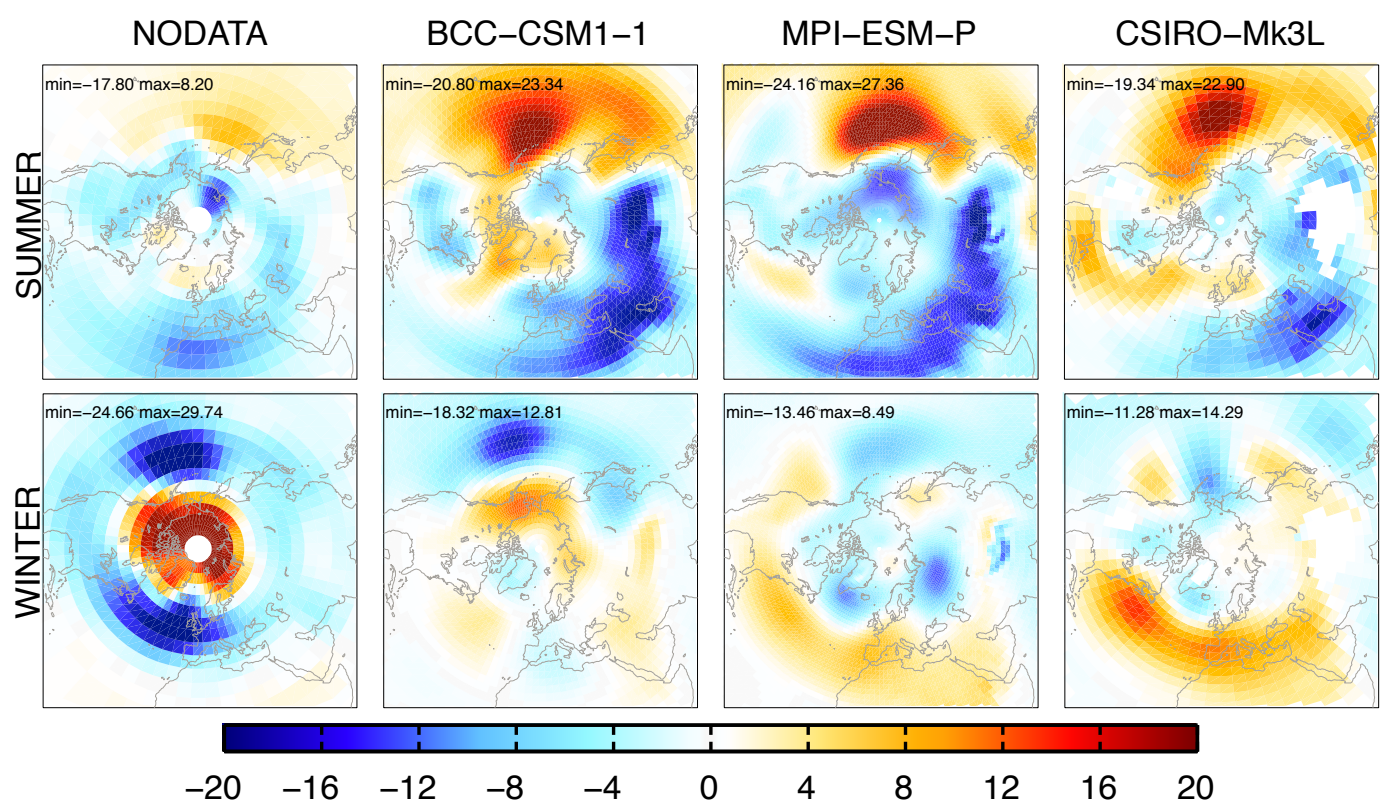

Fig. 3. Mid-Holocene geopotential height anomaly (in $\mathrm{m}$ ) at $800 \mathrm{hPa}$ for LOVECLIM without data assimilation (NODATA) and at $850 \mathrm{hPa}$ for the GCMs. Winter corresponds to DJF and summer to JJA. The reference period is $950-450 \mathrm{yr}$ BP.

reconstructions that represent relatively local-regional phenomena in coastal areas or close to fronts and thus not the mean open ocean conditions.

Additional information on the local agreement between model results and proxy-based reconstructions can be obtained by computing the root mean square error (RMSE) defined as

$\mathrm{RMSE}=\sqrt{\frac{\sum_{i=1}^{n}\left(\Delta T_{i}^{\mathrm{mod}}-\Delta T_{i}^{\mathrm{obs}}\right)^{2}}{n}}$,

where $n$ is the number of proxy-based reconstructions, $\Delta T_{i}^{\mathrm{obs}}$ is one particular mid-Holocene air or sea surface temperature anomaly derived from a proxy-based reconstruction and $\Delta T_{i}^{\text {mod }}$ is the corresponding modeled value. The minimum RMSE value for the different models is $1.7^{\circ} \mathrm{C} \mathrm{(Fig.} \mathrm{4).}$ This is larger than the mean signal, showing that the models have nearly no skill at the local scale as discussed in Hargreaves et al. (2013). Furthermore, the RMSE is larger for the oceanic proxy-based reconstructions than for continental proxy-based reconstructions in all the models. Actually, the models' results are in much better agreement between themselves than with the proxy-based reconstructions as the root mean square difference between different models, at locations for which proxy-based reconstructions are available, is close to $0.6^{\circ} \mathrm{C}$ on average (i.e., about a third of the RMSE shown in Fig. 4).

Nevertheless, this quantitative evaluation of model performance based on results at the grid scale could be considered as a too-strong test on several aspects. First, it does not take into account proxy-based reconstruction uncertainties.
Second, any small spatial shift in the model response compared to data would lead to large errors (e.g., Guiot et al., 1999). Third, model results and proxy-based reconstructions do not necessarily represent the climate at the same scale, leading to differences in the recorded signal, in particular on its magnitude. As a consequence, we have divided in Fig. 5a all the proxy-based reconstructions into three categories: (i) LOVECLIM agrees with the reconstructions with error bars, (ii) LOVECLIM agrees only with the sign of the reconstruction anomaly, and (iii) it does not agree with the sign of the reconstruction anomaly. This is displayed for the LOVECLIM model but the results are similar for the three GCMs (not shown). As this analysis is much less strict since it is less influenced by the magnitude of the anomaly, it leads to much more encouraging results than the conclusions derived from the analysis of the RMSE: LOVECLIM midHolocene simulation agrees with the sign of the anomaly of about two thirds of the proxy-based reconstructions (see the blue and the green markers in Fig. 5a). This agreement displays no clear dependance on the season, on the location of the reconstructions or on the type of the proxy-based reconstructions and no dominant spatial pattern can be defined from Fig. 5a.

\subsection{Simulations with data assimilation}

Although the results of simulations constrained by data assimilation will be presented in a quantitative way, our interpretation will often be more qualitative for the two following reasons. First, as mentioned in the methodology section, the proxy-based reconstruction uncertainty selected here has 


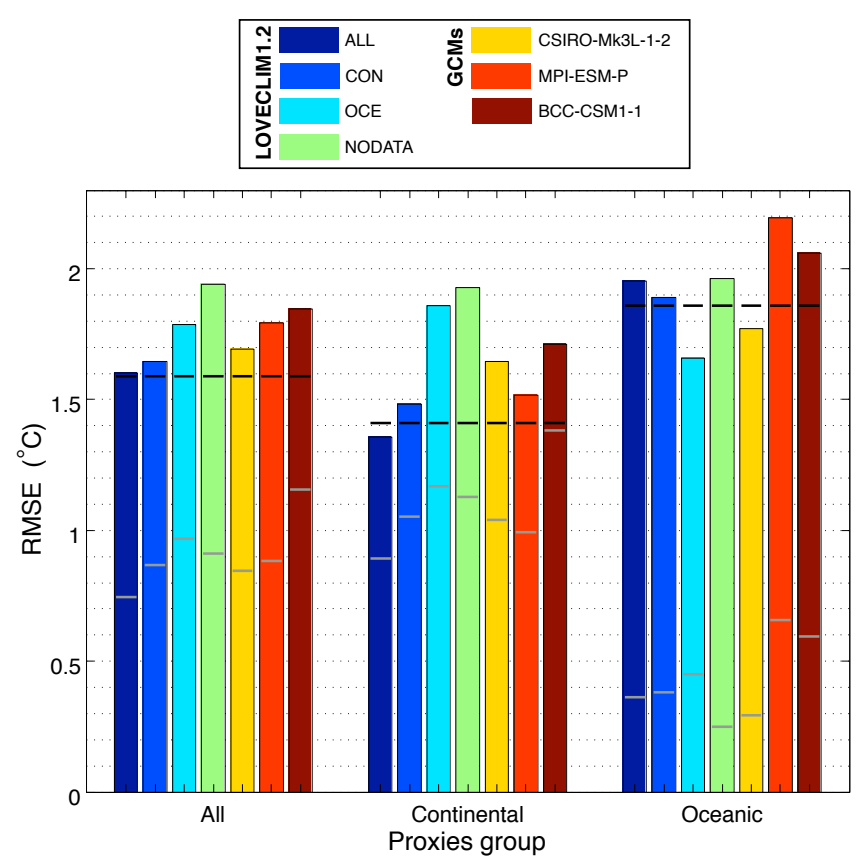

Fig. 4. From left to right: RMSE between the mid-Holocene anomalies of each simulation (LOVECLIM with and without data assimilation and the GCMs) and the proxy-based reconstruction anomalies for three groups of proxy-based reconstructions: all the proxybased reconstructions, the continental proxy-based reconstructions only and the oceanic proxy-based reconstructions only. The mean mid-Holocene signal (estimated as the standard deviation of the anomalies) for the proxy-based reconstructions and the model are the black and the grey horizontal bars, respectively.

a potential influence on the amplitude of the difference between the simulations with and without data assimilation. Second, the disagreement between LOVECLIM without data assimilation and proxy-based reconstructions is large. Although some improvements are due to data assimilation, the obtained model state is still not fully consistent with all the proxy-based reconstructions. This would require including additional control parameters in the data assimilation process, for instance perturbation of some model parameters, or alternative estimates of the uncertainty of the proxy-based reconstructions. This specific experimental design is out of the scope of this paper, as we would like to focus, in this first study of the mid-Holocene climate, on an estimate of compatibilities between models and proxy-based reconstructions using the standard model configuration and interpretation of the proxy-based reconstructions.

By construction, the data-assimilation method applied in LOVECLIM for the mid-Holocene period provides with results that are locally more consistent with the proxy-based reconstructions that are assimilated than with any other simulation performed without data assimilation selected in this study (Fig. 4). Indeed, the simulation constrained by all the proxy-based reconstructions displays the RMSE of $1.6^{\circ} \mathrm{C}$, which is $15 \%$ closer to the proxy-based reconstruction anomalies compared to the model without data assimilation. The RMSE between this simulation and the reconstructions is thus of the same magnitude as the mean signal of the proxy-based reconstructions from the mid-Holocene $\left(1.6^{\circ} \mathrm{C}\right)$. The assimilation of the continental reconstructions alone gives the RMSE of $1.5^{\circ} \mathrm{C}$, which corresponds to model results that are $22 \%$ closer to the proxy-based reconstructions that are assimilated compared to the model results without data assimilation. Finally, the data assimilation of the oceanic proxy-based reconstructions alone provides results that are $15 \%$ closer to those oceanic proxy-based reconstructions, inducing almost a doubling of the simulated oceanic signal compared to the simulation without data assimilation.

Figure 4 shows also that the assimilation process in ALL leads LOVECLIM to be more consistent with the continental proxy-based reconstructions than with the oceanic ones, which is due to the combination of two effects. First, the estimated error of the continental proxy-based reconstructions is smaller than the oceanic proxy-based records error (Table 1), which means that in the computation of the likelihood a larger weight is given to the continental archives. Second, the model's atmospheric fields and the surface temperature over land have a greater variance than the oceanic ones. Among the ensemble of simulations, it is thus more common to have members that are in agreement with continental proxy-based reconstructions. This leads to a larger impact from the continental proxy-based reconstructions if both domains are assimilated together and to strong similarities between the simulation constrained by all the proxy-based reconstructions and the one that is based on the continental proxy-based reconstructions only.

Although data assimilation only marginally reduces the RMSE between model and reconstructions, the amount of proxy-based reconstructions for which LOVECLIM does not agree with the sign of the anomalies decreases by about $20 \%$ in OCE and about $30 \%$ in CON and ALL compared to NODATA (Fig. 5). This is mainly caused in CON and ALL by a slight summer warming over northeastern Europe, the Barents sea and the Kara sea and by a summer cooling around Lake Baikal as well as by a winter warming from northeastern Europe to Lake Baikal, over the north of Greenland and over the central part of North America (Fig. 6). In these simulations, the improvement of sea surface temperature is mainly related to a warming along the coast of North America at about $40^{\circ} \mathrm{N}$. In the simulation OCE the higher number of proxy-based reconstructions that have the same anomalies as the model is mainly due to an annual warming of the North Atlantic and a summer warming in the North Pacific close to the west coast at $45^{\circ} \mathrm{N}$ (Fig. 6). Consequently, data assimilation drives the LOVECLIM model to a state that is maybe still not in the range of the anomalies derived from the proxies but that is at least more consistent with the sign of their changes. 


$\begin{array}{lll}\square \text { Pollen } & \diamond \text { Ice core } i \text { Mg/Ca } \\ \triangle \text { Speleothem } & \bigcirc \text { Alkenone } i \text { Foraminifera }\end{array}$

(a) SIMULATION NODATA

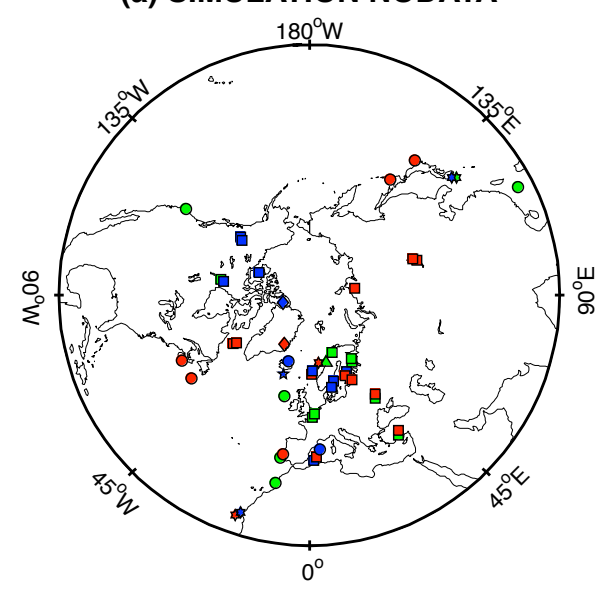

(c) SIMULATION CON

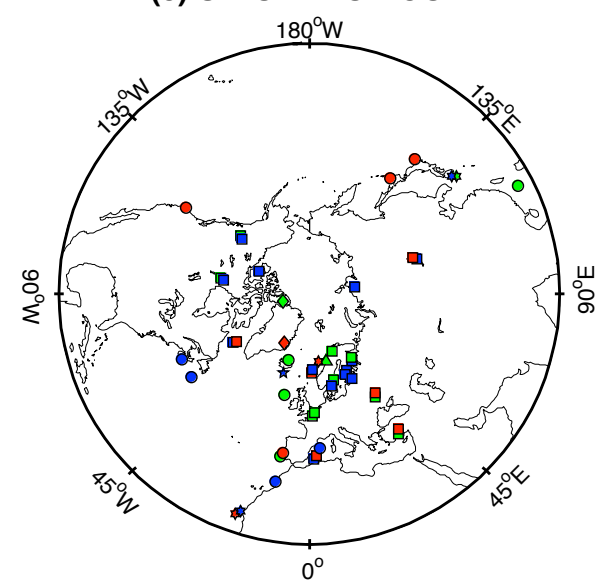

(b) SIMULATION ALL

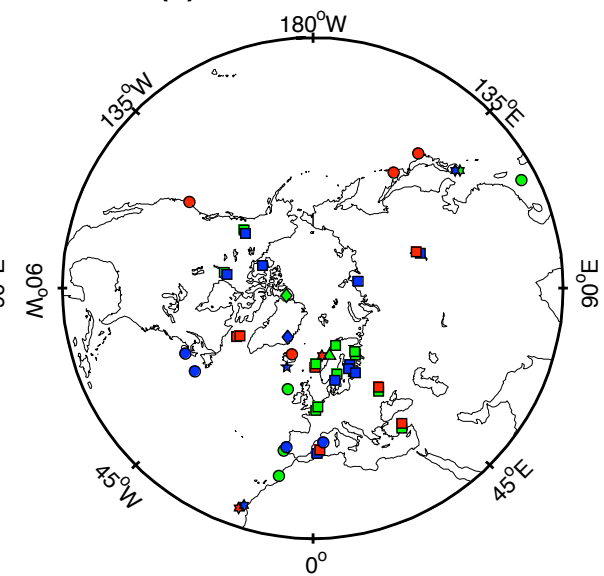

(d) SIMULATION OCE

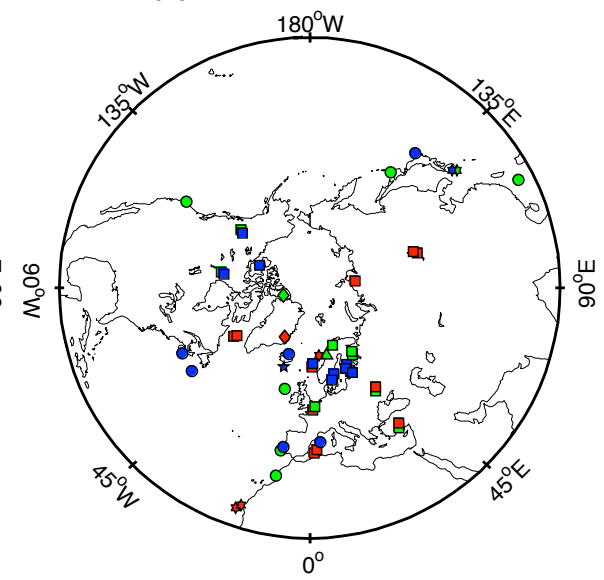

Fig. 5. Agreement between the mid-Holocene anomalies in LOVECLIM and in the proxy-based reconstructions. Each marker type corresponds to a different proxy-based reconstruction group. It is in green when the model agrees with the proxy-based reconstruction record within the error bars; in blue, when the model agrees only with the sign of the anomaly; in red, when the model does not agree on the sign of the anomaly. If more than one proxy-based reconstruction is given at the same location, the markers representing the proxy-based reconstructions are slightly shifted for improved readability.

The three experiments with data assimilation also allow us to test the influence of the data assimilation over the different domains (continent and ocean) on all the proxy-based reconstructions by grouping them in three categories (Fig. 7), but on different basis compared to Fig. 5. The first category consists in the proxy-based reconstructions for which LOVECLIM results without data assimilation were already consistent with the reconstructed signal, i.e., the difference between model results and proxy-based reconstructions is smaller than the error assigned here. Moreover, assimilation of these proxy-based reconstructions does not deteriorate the consistency between the model results with data assimilation and the signal recorded by the proxy. This category concerns $22 \%$ of all the proxy-based reconstructions used in this study. These reconstructions can be identified individually on the basis of the numbers on Fig. 1, using Table 1 . The second category ( $45 \%$ of all the proxy-based reconstructions) deals with the reconstructions that satisfy the two following criteria: (i) at least in one of the two simulations performed with data assimilation, in which these proxybased reconstructions are used, they are more consistent with the results with data assimilation than with the results without data assimilation. (ii) These proxy-based reconstructions are not less consistent with the results with data assimilation than with the results without data assimilation if they do not comply with the first rule. This corresponds to all the continental (oceanic) proxy-based reconstructions for which the anomaly difference in absolute value decreases by at least 


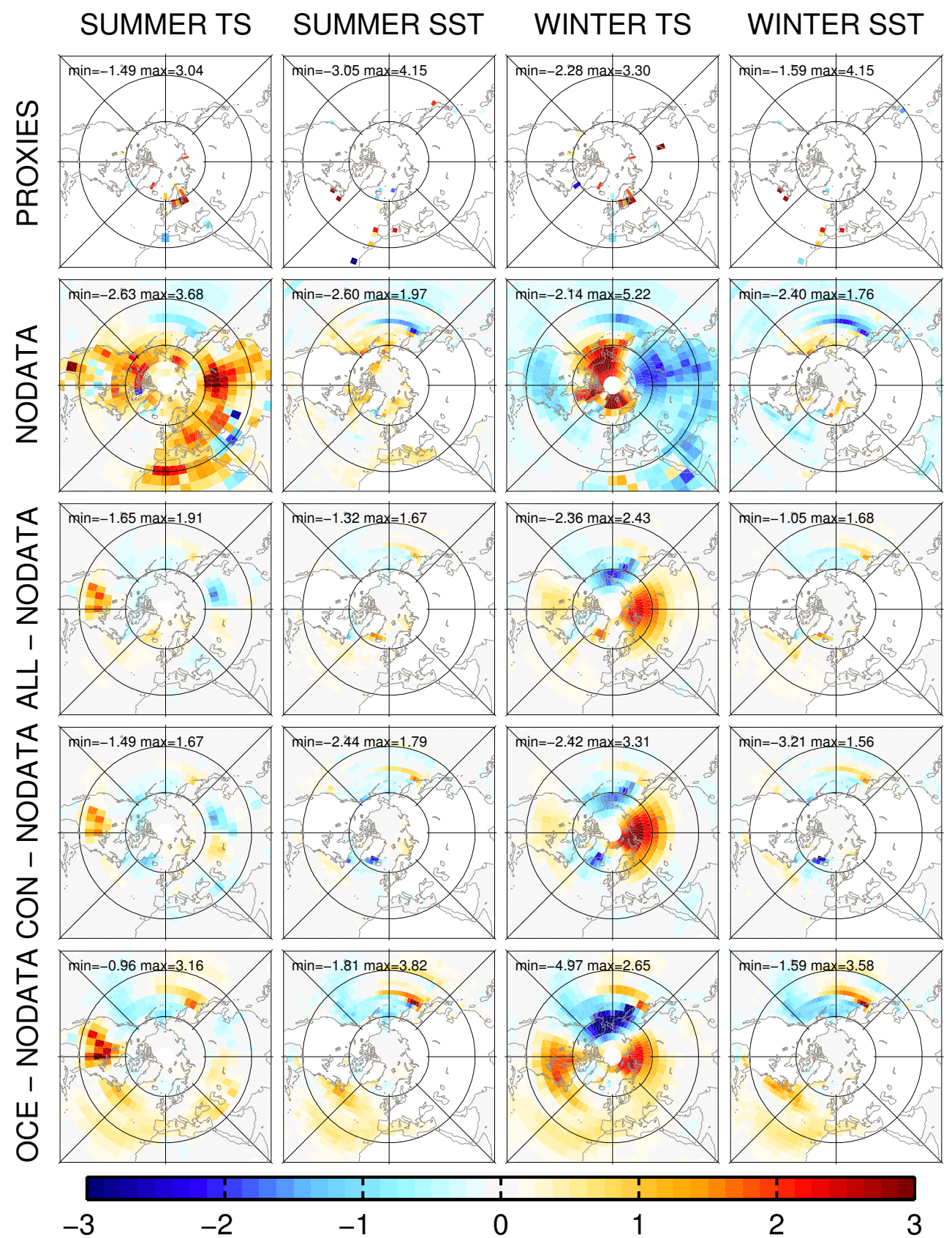

Fig. 6. Mid-Holocene air and sea surface temperature anomaly $\left({ }^{\circ} \mathrm{C}\right)$ for the proxy-based reconstructions and the LOVECLIM simulation performed without data assimilation (NODATA). The reference period is 950-450 yr BP. Differences between the three simulations performed with data assimilation (ALL, CON and OCE) and the simulation NODATA $\left({ }^{\circ} \mathrm{C}\right.$ ). Winter corresponds to DJF and summer to JJA.

$5 \%$ in ALL and/or CON (ALL and/or OCE) and does not increase by more than $5 \%$ in the other(s) simulation(s) with data assimilation. For $66 \%$ of the proxy-based reconstructions included in this category ( $28 \%$ of all the reconstructions), the anomalies in the three simulations with data assimilation are closer to the proxy-based reconstruction anomaly than in the model without data assimilation. This implies that the model dynamics is able to propagate the signal brought by the assimilated proxy-based reconstructions towards the locations where no data is assimilated and also that the information brought by this $28 \%$ of reconstructions is coherent. The third category (33\% of all the proxy-based reconstructions) includes the reconstructions that are either (i) less consistent (5\% threshold) in at least one of the three simulations with data assimilation compared with the simulation without data assimilation, or that are (ii) not more consistent with any 

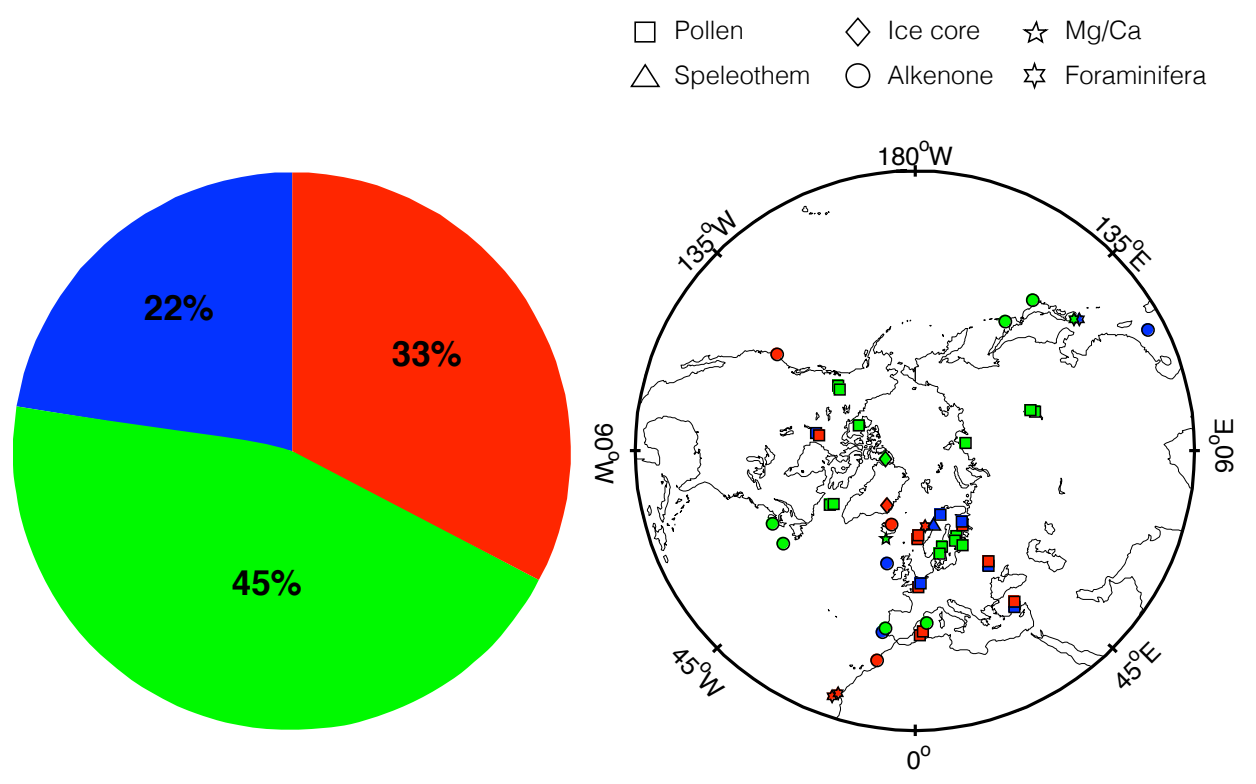

Fig. 7. Percentage and location of mid-Holocene proxy-based reconstructions for which (i) the modeled anomalies without data assimilation and in the three simulations with data assimilation are always within the estimated uncertainty of a particular proxy-based reconstruction (in blue); (ii) the modeled anomaly of at least one simulation with data assimilation is more consistent with the proxy-based reconstruction at the same location if it is assimilated and is not less consistent in the other simulations with data assimilation (in green); (iii) at least one of the three simulations with data assimilation is less consistent with the proxy-based reconstructions than the simulation without data assimilation or that no improvement is brought when they are assimilated (in red). On the map, if more than one proxy-based reconstruction is given at the same location, the markers representing those reconstructions are slightly shifted for improved readability. Each marker type corresponds to a different proxy-based reconstruction group.

simulation with data assimilation than with the simulation without data assimilation. In the majority of the cases ( $70 \%$ of the proxy-based reconstructions of this category), this corresponds to reconstructions on land (ocean) whose differences with model results are larger in OCE (CON) than in NODATA. As a consequence, the model dynamics suggests an incompatibility between the signal reconstructed from the different types of proxies as improving one realm (land or ocean) deteriorates the results in the other one. This could be due to several processes such as a bias in the teleconnections simulated by the models, in the interpretation of the signal recorded by the proxy, in the way models and proxy-based reconstructions are compared. Our experimental design does not allow us to determine which of those is dominant for each proxy-based reconstruction but it indicates that a special attention has to be given to those regions to understand the causes of this disagreement. This is the case, for instance, for the continental proxy-based reconstruction N42 whose signal is opposite to the one depicted by the oceanic proxybased reconstructions N4, N7, N9 and N10. Another example is the oceanic proxy-based reconstruction N15 whose signal shows a summer negative anomaly opposite (i) to the positive one illustrated by the nearby continental proxy-based reconstructions and (ii) to the alkenone-based sea surface temperature reconstruction derived from the same core which depicts a positive anomaly (Calvo et al., 2002). This incom- patibility consolidates the interpretation of Risebrobakken et al. (2003) that this proxy-based reconstruction should not be considered as an estimate of surface temperature. Finally, the proxy-based reconstructions that are never more consistent with the simulations performed with data assimilation, indicate a profound disagreement between their information and the model physics. For instance, the model is not able to reproduce the summer (winter) cooling over southwestern (northwestern) Europe depicted by the proxy-based reconstructions N43 (N38) with data assimilation as already mentioned for LOVECLIM and the GCMs without data assimilation.

The improvement brought by data assimilation can be related to modifications of both winds and ocean currents. The atmospheric circulation changes associated with data assimilations in ALL, CON and OCE have a lower magnitude than the one in response to the forcing in NODATA for the summer, while for the winter, these changes are at least of the same magnitude as the model response to forcing (Fig. 8). All the experiments constrained by data assimilation display a decrease in geopotential height at high latitudes and an increase at midlatitudes in winter compared to NODATA, the signal in summer being weaker. This strengthens the westerlies over the North Atlantic inducing a winter warming from the northern Europe to Lake Baikal as well as over North America (Fig. 6). This is consistent with the findings 


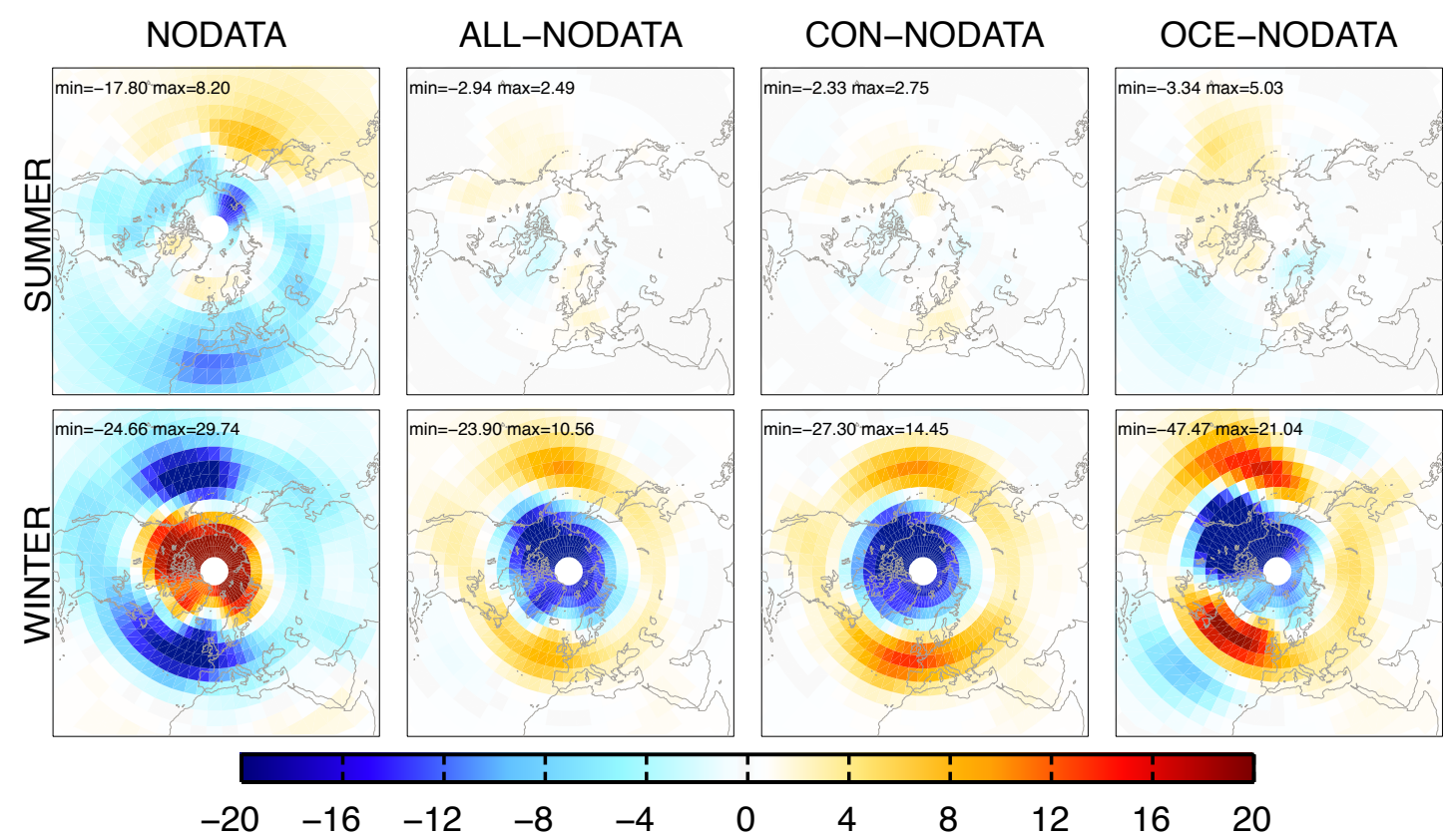

Fig. 8. Mid-Holocene geopotential height anomaly at $800 \mathrm{hPa}$ (in $\mathrm{m}$ ) for the simulation NODATA. The reference period is $950-450 \mathrm{yr}$ BP. Difference between the three simulations performed with data assimilation (ALL, CON and OCE) and the simulation NODATA. Winter corresponds to DJF and summer to JJA.
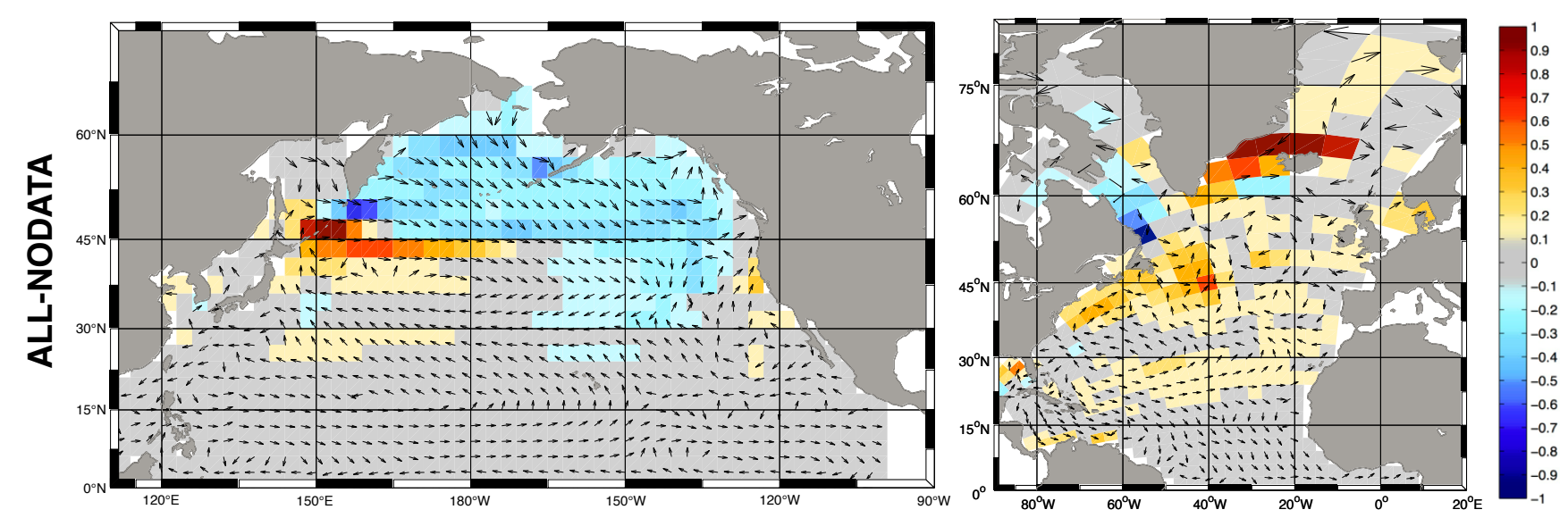

Fig. 9. Mean annual mid-Holocene difference of sea surface temperature $\left({ }^{\circ} \mathrm{C}\right)$ and surface oceanic current for the Pacific and the Atlantic oceans between the simulations ALL and NODATA. The size of the arrows is not proportional to their velocity in order to improve the readability of the maps since the objective is to show the current direction and not its strength.

of Rimbu et al. (2003), who indicate, using alkenone data, that the NAO was more likely in a positive pattern phase during the mid-Holocene with respect to our reference period. The induced surface temperature changes are more pronounced during the winter since during these months the atmospheric circulation endures the stronger changes. Furthermore, changes in atmospheric circulation are stronger in the OCE simulation than in the simulations ALL and CON (Fig. 8). This induces stronger westerlies over the Pacific and, therefore, a stronger warming over North America
(Fig. 6). In winter the pattern over the North Atlantic is more complex in OCE than in the other experiments, with stronger westerlies northward of $50^{\circ} \mathrm{N}$ and weaker ones between 40 and $50^{\circ} \mathrm{N}$.

The spatial structure of the changes in annual mean sea surface temperature and surface current between each simulation performed with data assimilation and the simulation NODATA are similar, both in the North Atlantic and the North Pacific. Therefore, the figures are shown only for ALL (Fig. 9). In the Pacific, the strengthening of the 
westerlies produces an intensification of the northern branch of the North Pacific Gyre, which is stronger on the eastern part compared to the western part. This tends (i) to transport the warmer water from the northern extension of the Kuroshio eastward (around $45^{\circ} \mathrm{N}$ ). It leads to warmer sea surface temperature and a warming of the atmosphere by the ocean. (ii) This also transports the colder western and northern Pacific water (cooled by the Siberian winds) toward the warmer eastern Pacific following the gyre cycle. The pattern is most marked in the simulation OCE than in the other two (Fig. 6) as the westerlies are more intensified in this simulation. Additionally, the northward shift of the westerlies slows down the winds around $30^{\circ} \mathrm{N}$ in the western Pacific, which induces a reduced heat loss by evaporation and, therefore, a warmer sea surface temperature at this location. These two processes occur also in the Atlantic Ocean. The first is associated with an intensification of the Gulf Stream current at around $40^{\circ} \mathrm{N}$ due to stronger winds at this location (Fig. 8), which leads to a warming of the western Atlantic between 40 and $50^{\circ} \mathrm{N}$. The second one leads to a warming of the Atlantic between 20 and $30^{\circ} \mathrm{N}$ induced by weaker winds. Finally, around $65^{\circ} \mathrm{N}$, a localized warming results from the ice front shifting. This feature is not robust as it is not present in all our experiments. The meridional overturning circulation is also slightly stronger in the Atlantic in the simulations with data assimilation compared to NODATA. The difference between the maximum in ALL-CON-OCE and the maximum in NODATA is, however, smaller than $1 \mathrm{~Sv}$, which corresponds to an increase of between $2(5 \mathrm{TW})$ and $8 \%$ (18 $\mathrm{TW}$ ) in the meridional heat transport at $30^{\circ} \mathrm{S}$ compared to the mean value in NODATA, contributing to some extent to the large-scale warming of the North Atlantic.

\section{Conclusions}

The conclusions derived from our analysis of simulations performed with GCMs and with LOVECLIM with and without data assimilation for the mid-Holocene can be summarized as follows.

1. In agreement with previous studies, a direct evaluation of the mean error of mid-Holocene simulations performed without data assimilation suggests that models have nearly no skill at the local scale compared to proxy-based reconstructions and that the models agree much better between themselves than with proxybased reconstructions. A comparison of the dominant patterns and of the sign of the changes, taking into account the uncertainties in proxy-based reconstructions, leads to a much better consistency between models and data although clear disagreements remain in some regions.
2. The simulations with data assimilation are more consistent with the sign of the proxy-based reconstruction anomalies and the spatial pattern of the changes than the simulation without data assimilation.

3. However, for a third of the proxy-based reconstructions, data assimilation does not bring any improvement to the agreement with proxy-based reconstructions. For some reconstructions, it is due to a fundamental inconsistency with model physics, but for the majority of the proxy-based reconstructions in this case, this is due to an incompatibility between the various proxy-based reconstructions according to the model physics; i.e., the model is not able to follow the signal recorded in all of them simultaneously. One clear strength of our methodology is to identify objectively those proxy-based reconstructions.

4. The methodology has also allowed identifying the mechanisms that lead to a better consistency between the model results and the proxy-based reconstructions. The dominant one, which is robust in all our experiments, is the strengthening of the westerlies at midlatitude that warm up northern Europe.

Acknowledgements. The authors acknowledge the constructive and precise comments of the two anonymous reviewers. We thank all the people who made the data available, in particular Guillaume Leduc, Joan O. Grimalt, Belen Martrat and Heikki Seppä. We acknowledge the World Climate Research Programme's Working Group on Coupled Modelling, which is responsible for CMIP. For CMIP the US Department of Energy's Program for Climate Model Diagnosis and Intercomparison provides coordinating support and led development of software infrastructure in partnership with the Global Organization for Earth System Science Portals. We acknowledge D. Roche for making available the ice sheet forcing data for the LOVECLIM model. A. Mairesse also wishes to thank Marit-Solveig Seidenkrantz and Anne de Vernal for the very useful discussions about the oceanic proxy-based reconstructions as well as Eric Wolff and Joëel Guiot about the ice-core and the pollen data, respectively. H. Goosse is a senior research associate with the Fonds National de la Recherche Scientifique (F.R.S. - FNRS-Belgium). The research leading to these results has received funding from the European Union's Seventh Framework programme (FP7/2007-2013) under grant agreement no. 243908, "Past4Future: Climate change - Learning from the past climate". Computational resources have been provided by the supercomputing facilities of the Université catholique de Louvain (CISM/UCL) and the Consortium des Equipements de Calcul Intensif en Fédération Wallonie Bruxelles (CECI) funded by FRS-FNRS. This is Past4Future contribution no. 61.

Edited by: G. M. Ganssen 


\section{References}

Andreev, A. A., Tarasov, P. E., Siegert, C., Ebel, T., Klimanov, V. A., Melles, M., Bobrov, A. A., Dereviagin, A. Y., Lubinski, D. J., and Hubberten, H.-W.: Late Pleistocene and Holocene vegetation and climate on the northern Taymyr Peninsula, Arctic Russia, Boreas, 32, 484-505, 2003.

Antonsson, K., Brooks, S. J., Seppä, H., Telford, R. J., and Birks, H. J. B.: Quantitative palaeotemperature records inferred from fossil pollen and chironomid assemblages from Lake Gilltjärnen, northern central Sweden, J. Quaternary Sci., 21, 831-841, 2006.

Barron, J. A., Heusser, L., Herbert, T., and Lyle, M.: Highresolution climatic evolution of coastal northern California during the past 16,000 years, Paleoceanography, 18, 1020, doi:10.1029/2002PA000768, 2003.

Bartlein, P. J., Harrison, S. P., Brewer, S., Connor, S., Davis, B. A. S., Gajewski, K., Guiot, J., Harrison-Prentice, T. I., Henderson, A., Peyron, O., Prentice, I. C., Scholze, M., Seppä, H., Shuman, B., Sugita, S., Thompson, R. S., Viau, A. E., Williams, J., and Wu, H.: Pollen-based continental climate reconstructions at 6 and 21 ka: a global synthesis, Clim. Dynam., 37, 775-802, 2011.

Bendle, J. and Rosell-Melé, A.: High-resolution alkenone sea surface temperature variability on the North Icelandic Shelf: implications for Nordic Seas palaeoclimatic development during the Holocene, The Holocene, 17, 9-24, doi:10.1177/0959683607073269, 2007.

Berger, A.: Long-term variations of daily insolation and quaternary climatic changes, J. Atmos. Sci., 35, 2362-2367, 1978.

Birks, H., Heiri, O., Seppä, H., and Bjune, A.: Strengths and weaknesses of quantitative climate reconstructions based on lateQuaternary biological proxies, Open Ecol. J., 3, 68-110, 2010.

Boer, G.: The ratio of land to ocean temperature change under global warming, Clim. Dynam., 37, 2253-2270, 2011.

Braconnot, P., Otto-Bliesner, B., Harrison, S., Joussaume, S., Peterchmitt, J.-Y., Abe-Ouchi, A., Crucifix, M., Driesschaert, E., Fichefet, Th., Hewitt, C. D., Kageyama, M., Kitoh, A., Laîné, A., Loutre, M.-F., Marti, O., Merkel, U., Ramstein, G., Valdes, P., Weber, S. L., Yu, Y., and Zhao, Y.: Results of PMIP2 coupled simulations of the Mid-Holocene and Last Glacial Maximum Part 1: experiments and large-scale features, Clim. Past, 3, 261277, doi:10.5194/cp-3-261-2007, 2007a.

Braconnot, P., Otto-Bliesner, B., Harrison, S., Joussaume, S., Peterchmitt, J.-Y., Abe-Ouchi, A., Crucifix, M., Driesschaert, E., Fichefet, Th., Hewitt, C. D., Kageyama, M., Kitoh, A., Loutre, M.-F., Marti, O., Merkel, U., Ramstein, G., Valdes, P., Weber, L., Yu, Y., and Zhao, Y.: Results of PMIP2 coupled simulations of the Mid-Holocene and Last Glacial Maximum - Part 2: feedbacks with emphasis on the location of the ITCZ and mid- and high latitudes heat budget, Clim. Past, 3, 279-296, doi:10.5194/cp-3-279-2007, 2007b.

Braconnot, P., Harrison, S., Kageyama, M., Bartlein, P., MassonDelmotte, V., Abe-Ouchi, A., Otto-Bliesner, B., and Zhao, Y.: Evaluation of climate models using palaeoclimatic data, Nat. Clim. Change, 2, 417-424, 2012.

Brewer, S., Guiot, J., and Barboni, D.: Pollen methods and studies: use of pollen as climate proxies, in: Encyclopedia of Quaternary Science, edited by: Elias, S. A., Elsevier, Oxford, 2497-2508, 2007a.
Brewer, S., Guiot, J., and Torre, F.: Mid-Holocene climate change in Europe: a data-model comparison, Clim. Past, 3, 499-512, doi:10.5194/cp-3-499-2007, 2007b.

Brook, E. J.: Ice core methods: overview, in: Encyclopedia of Quaternary Science, edited by: Elias, S. A., Elsevier, Oxford, $2497-$ 2508, 2007.

Brovkin, V., Ganopolski, A., and Svirezhev, Y.: A continuous climate-vegetation classification for use in climate-biosphere studies, Ecol. Model., 101, 251-261, 1997.

Calvo, E., Grimalt, J., and Jansen, E.: High resolution $\mathrm{U}_{37}^{K}$ sea surface temperature reconstruction in the Norwegian Sea during the Holocene, Quaternary Sci. Rev., 21, 1385-1394, 2002.

Claussen, M., Kubatzki, C., Brovkin, V., Ganopolski, A., Hoelzmann, P., and Pachur, H.: Simulation of an abrupt change in Saharan vegetation in the mid-Holocene, Geophys. Res. Lett., 26, 2037-2040, 1999.

Clegg, B. F., Clarke, G. H., Chipman, M. L., Chou, M., Walker, I. R., Tinner, W., and Hu, F. S.: Six millennia of summer temperature variation based on midge analysis of lake sediments from Alaska, Quaternary Sci. Rev., 29, 3308-3316, 2010.

Crespin, E., Goosse, H., Fichefet, T., Mairesse, A., and SallazDamaz, Y.: Arctic climate over the past millennium: annual and seasonal responses to external forcings, The Holocene, 23, 321329, 2013.

Crucifix, M.: Modelling the climate of the Holocene, in: Natural Climate variability and Global Warming: a Holocene Perspective, edited by: Battarbee, R. W. and Binney, H., WileyBlackwell, 98-122, Oxford, UK, 2008.

Davis, B. A. S., Brewer, S., Stevenson, A. C., and Guiot, J.: The temperature of Europe during the Holocene reconstructed from pollen data, Quaternary Sci. Rev., 22, 1701-1716, 2003.

deMenocal, P., Ortiz, J., Guilderson, T., and Sarnthein, M.: Coherent high- and low-latitude climate variability during the Holocene warm period, Science, 288, 2198-2202, 2000.

Dubinkina, S., Goosse, H., Sallaz-Damaz, Y., Crespin, E., and Crucifix, M.: Testing a particle filter to reconstruct climate changes over past centuries, Int. J. Bifurcat. Chaos, 21, 3611-3618, doi:10.1142/S0218127411030763, 2011.

Esparza, M.: Estudi de la variabilitat climàtica de l'oceà Atlàntic nord durant l'holocè mitjançant biomarcadors moleculars, Master's thesis, Autonomous University of Barcelona, Faculty of Sciences, Bellaterra (Cerdanyola del Vallès), Barcelona, Spain, 2005.

Flückiger, J., Monnin, E., Stauffer, B., Schwander, J., Stocker, T. F., Chappellaz, J., Raynaud, D., and Barnola, J.-M.: High-resolution Holocene $\mathrm{N}_{2} \mathrm{O}$ ice core record and its relationship with $\mathrm{CH}_{4}$ and $\mathrm{CO}_{2}$, Global Biogeochem. Cy., 16, 10-1-10-8, 2002.

Gladstone, R., Ross, I., Valdes, P., Abe-Ouchi, A., Braconnot, P., Brewer, S., Kageyama, M., Kitoh, A., Legrande, A., Marti, O., Otto-Bliesner, B., Peltier, W. R., and Vettoretti, G.: MidHolocene NAO: a PMIP2 model intercomparison, Geophys. Res. Lett., 32, L16707, doi:10.1029/2005GL023596, 2005.

Goosse, H. and Fichefet, T.: Importance of ice-ocean interactions for the global ocean circulation: a model study, J. Geophys. Res., 104, 23337-23355, 1999.

Goosse, H., Renssen, H., Timmermann, A., Bradley, R. S., and Mann, M. E.: Using paleoclimate proxy-data to select optimal realisations in an ensemble of simulations of the climate of the past millennium, Clim. Dynam., 27, 165-184, 2006. 
Goosse, H., Brovkin, V., Fichefet, T., Haarsma, R., Huybrechts, P., Jongma, J., Mouchet, A., Selten, F., Barriat, P.-Y., Campin, J.M., Deleersnijder, E., Driesschaert, E., Goelzer, H., Janssens, I., Loutre, M.-F., Morales Maqueda, M. A., Opsteegh, T., Mathieu, P.-P., Munhoven, G., Pettersson, E. J., Renssen, H., Roche, D. M., Schaeffer, M., Tartinville, B., Timmermann, A., and Weber, S. L.: Description of the Earth system model of intermediate complexity LOVECLIM version 1.2, Geosci. Model Dev., 3, 603-633, doi:10.5194/gmd-3-603-2010, 2010.

Goosse, H., Crespin, E., Dubinkina, S., Loutre, M.-F., Mann, M. E., Renssen, H., Sallaz-Damaz, Y., and Shindell, D.: The role of forcing and internal dynamics in explaining the "Medieval Climate Anomaly", Clim. Dynam., 39, 2847-2866, 2012.

Grimalt, J. and Lopez, J.: Paleoceanography, biological proxies: alkenone paleothermometry from coccoliths, in: Encyclopedia of Quaternary Science, edited by: Elias, S. A., Elsevier, Oxford, 1610-1618, 2007.

Guiot, J., Boreux, J.-J., Braconnot, P., and Torre, F.: Data-model comparison using fuzzy logic in paleoclimatology, Clim. Dynam., 15, 569-581, 1999.

Harada, N., Ahagon, N., Sakamoto, T., Uchida, M., Ikehara, M., and Shibata, Y.: Rapid fluctuation of alkenone temperature in the southwestern Okhotsk Sea during the past 120 ky, Global Planet. Change, 53, 29-46, 2006.

Hargreaves, J. C., Annan, J. D., Ohgaito, R., Paul, A., and AbeOuchi, A.: Skill and reliability of climate model ensembles at the Last Glacial Maximum and mid-Holocene, Clim. Past, 9, 811823, doi:10.5194/cp-9-811-2013, 2013.

Heikkilä, M. and Seppä, H.: A 11,000 yr palaeotemperature reconstruction from the southern boreal zone in Finland, Quaternary Sci. Rev., 22, 541-554, 2003.

Herbert, T.: Alkenone paleotemperature determinations, in: Treatise on Geochemistry, edited by: Holland, H. D. and Turekian, K. K., Pergamon, Oxford, 391-432, 2003.

Isono, D., Yamamoto, M., Irino, T., Oba, T., Murayama, M., Nakamura, T., and Kawahata, H.: The 1500-year climate oscillation in the midlatitude North Pacific during the Holocene, Geology, 37 , 591, doi:10.1130/G25667A.1, 2009.

Jian, Z., Wang, P., Saito, Y., Wang, J., Pflaumann, U., Oba, T., and Cheng, X.: Holocene variability of the Kuroshio Current in the Okinawa Trough, northwestern Pacific Ocean, Earth Planet. Sc. Lett., 184, 305-319, 2000.

Joshi, M. M., Lambert, F.H., and Webb, M. J.: An explanation for the difference between twentieth and twenty-first century land-sea warming ratio in climate models, Clim. Dynam., 41, 1853-1869, 2013.

Juggins, S.: Quantitative reconstructions in palaeolimnology: new paradigm or sick science?, Quaternary Sci. Rev., 64, 20-32, 2013.

Kim, J., Meggers, H., Rimbu, N., Lohmann, G., Freudenthal, T., Müller, P., and Schneider, R.: Impacts of the North Atlantic gyre circulation on Holocene climate off northwest Africa, Geology, 35, 387, doi:10.1130/G23251A.1, 2007.

Lauritzen, S. and Lundberg, J.: Calibration of the speleothem delta function: an absolute temperature record for the Holocene in northern Norway, The Holocene, 9, 659, doi:10.1191/095968399667823929, 1999.

Leduc, G., Schneider, R., Kim, J.-H., and Lohmann, G.: Holocene and Eemian sea surface temperature trends as revealed by alkenone and $\mathrm{Mg} / \mathrm{Ca}$ paleothermometry, Quaternary Sci. Rev., 29, 989-1004, 2010.

Lohmann, G., Pfeiffer, M., Laepple, T., Leduc, G., and Kim, J.H.: A model-data comparison of the Holocene global sea surface temperature evolution, Clim. Past, 9, 1807-1839, doi:10.5194/cp-9-1807-2013, 2013.

Lorenz, S. J., Kim, J.-H., Rimbu, N., Schneider, R. R., and Lohmann, G: Orbitally driven insolation forcing on Holocene climate trends: Evidence from alkenone data and climate modeling, Paleoceanography, 21, PA1002, doi:10.1029/2005PA001152, 2006.

Marcott, S. A., Shakun, J. D., Clark, P. U., and Mix, A. C.: A Reconstruction of Regional and Global Temperature for the Past 11,300 Years, Science, 339, 1198-1201, 2013.

Marsland, S., Haak, H., Jungclaus, J., Latif, M., and Röske, F.: The Max-Planck-Institute global ocean/sea ice model with orthogonal curvilinear coordinates, Ocean Model., 5, 91-127, 2003.

Martrat, B.: Studies of sedimentary organic matter to infer rapid climatic changes at the Barents and Iberian continental margins on centennial time resolution over the past four climate cycles of the Quaternary (ca. 420,000 years), Ph. D. thesis, UPC, CSIC, Barcelona, Spain, 2007.

Martrat, B., Grimalt, J., Shackleton, N., de Abreu, L., Hutterli, M., and Stocker, T.: Four climate cycles of recurring deep and surface water destabilizations on the Iberian margin, Science, 317, 502507, doi:10.1126/science.1139994, 2007.

Mathiot, P., Goosse, H., Crosta, X., Stenni, B., Braida, M., Renssen, H., Van Meerbeeck, C. J., Masson-Delmotte, V., Mairesse, A., and Dubinkina, S.: Using data assimilation to investigate the causes of Southern Hemisphere high latitude cooling from 10 to $8 \mathrm{ka} \mathrm{BP}$, Clim. Past, 9, 887-901, doi:10.5194/cp9-887-2013, 2013.

Mock, C. J.: Paleoclimate: introduction, why study paleoclimatology ?, in: Encyclopedia of Quaternary Science, edited: by Elias, S. A., Elsevier, 1867-1872, Oxford, UK, 2007.

Müller, P. J., Kirst, G., Ruhland, G., von Storch, I., and RosellMelé, A.: Calibration of the alkenone paleotemperature index $\mathrm{U}_{K}^{37}$ based on core-tops from the eastern South Atlantic and the global ocean $\left(60^{\circ} \mathrm{N}-60^{\circ} \mathrm{S}\right)$, Geochim. Cosmochim. Ac., 62, 1757-1772, 1998.

Ohlwein, C. and Wahl, E.: Review of probabilistic pollenclimate transfer methods, Quaternary Sci. Rev., 31, 17-29, doi:10.1016/j.quascirev.2011.11.002, 2011.

Opsteegh, J. D., Haarsma, R. J., Selten, F. M., and Kattenberg, A.: ECBILT: a dynamic alternative to mixed boundary conditions in ocean models, Tellus A, 50, 348-367, 1998.

Ortiz, J. D.: Paleoceanography, biological proxies: temperature proxies, census counts, in: Encyclopedia of Quaternary Science, edited by: Elias, S. A., Elsevier, Oxford, 1692-1699, 2007.

Pelejero, C., Grimalt, J., Heilig, S., Kienast, M., and Wang, L.: High-resolution UK37 temperature reconstructions in the South China Sea over the past 220 kyr, Paleoceanography, 14, 224-231, 1999.

Peltier, W.: Global glacial isostasy and the surface of the ice-age Earth: the ICE-5G (VM2) model and GRACE, Annu. Rev. Earth Pl. Sc., 32, 111-149, 2004.

Peros, M. and Gajewski, K.: Holocene climate and vegetation change on Victoria Island, western Canadian Arctic, Quaternary Sci. Rev., 27, 235-249, 2008. 
Phipps, S. J., Rotstayn, L. D., Gordon, H. B., Roberts, J. L., Hirst, A. C., and Budd, W. F.: The CSIRO Mk3L climate system model version 1.0 - Part 1: Description and evaluation, Geosci. Model Dev., 4, 483-509, doi:10.5194/gmd-4-483-2011, 2011.

Pollard, D. and DeConto, R.: Modelling West Antarctic ice sheet growth and collapse through the past five million years, Nature, 458, 329-332, 2009.

Raddatz, T., Reick, C., Knorr, W., Kattge, J., Roeckner, E., Schnur, R., Schnitzler, K.-G., Wetzel, P., and Jungclaus, J.: Will the tropical land biosphere dominate the climate-carbon cycle feedback during the twenty-first century ?, Clim. Dynam., 29, 565-574, 2007.

Renssen, H., Goosse, H., Fichefet, T., Brovkin, V., Driesschaert, E., and Wolk, F.: Simulating the Holocene climate evolution at northern high latitudes using a coupled atmosphere-sea iceocean-vegetation model, Clim. Dynam., 24, 23-43, 2005.

Renssen, H., Seppä, H., Heiri, O., Roche, D., Goosse, H., and Fichefet, T.: The spatial and temporal complexity of the Holocene thermal maximum, Nat. Geosci., 2, 411-414, 2009.

Renssen, H., Seppä, H., Crosta, X., Goosse, H., and Roche, D.: Global characterization of the Holocene Thermal Maximum, Quaternary Sci. Rev., 48, 7-19, 2012.

Rimbu, N., Lohmann, G., Kim, J.-H., Arz, H. W., and Schneider, R.: Arctic/North Atlantic Oscillation signature in Holocene sea surface temperature trends as obtained from alkenone data, Geophys. Res. Lett., 30, 1280, doi:10.1029/2002GL016570, 2003.

Risebrobakken, B., Jansen, E., Andersson, C., Mjelde, E., and Hevrøy, K.: A high-resolution study of Holocene paleoclimatic and paleoceanographic changes in the Nordic Seas, Paleoceanography, 18, 1017, doi:10.1029/2002PA000764, 2003.

Rodrigues, T., Grimalt, J., Abrantes, F., Flores, J., and Lebreiro, S.: Holocene interdependences of changes in sea surface temperature, productivity, and fluvial inputs in the Iberian continental shelf (Tagus mud patch), Geochem. Geophys. Geosys., 10, Q07U06, doi:10.1029/2008GC002367, 2009.

Sachs, J. P.: Cooling of Northwest Atlantic slope waters during the Holocene, Geophys. Res. Lett., 34, L03609, doi:10.1029/2006GL028495, 2007.

Samtleben, C. and Bickert, T.: Coccoliths in sediment traps from the Norwegian Sea, Mar. Micropaleontol., 16, 39-64, 1990.

Sarmaja-Korjonen, K. and Seppä, H.: Abrupt and consistent responses of aquatic and terrestrial ecosystems to the $8200 \mathrm{cal}$. $\mathrm{yr}$ cold event: a lacustrine record from Lake Arapisto, Finland, The Holocene, 17, 457-467, 2007.

Schneider, B., Leduc, G., and Park, W.: Disentangling seasonal signals in Holocene climate trends by satellitemodel-proxy integration, Paleoceanography, 25, PA4217, doi:10.1029/2009PA001893, 2010.
Seppä, H. and Birks, H.: July mean temperature and annual precipitation trends during the Holocene in the Fennoscandian treeline area: pollen-based climate reconstructions, The Holocene, 11, 527-539, 2001.

Seppä, H. and Birks, H.: Holocene climate reconstructions from the Fennoscandian tree-line area based on pollen data from Toskaijavri, Quaternary Res., 57, 191-199, 2002.

Seppä, H. and Poska, A.: Holocene annual mean temperature changes in Estonia and their relationship to solar insolation and atmospheric circulation patterns, Quaternary Res., 61, 22-31, 2004.

Seppä, H., Hammarlund, D., and Antonsson, K.: Low-frequency and high-frequency changes in temperature and effective humidity during the Holocene in south-central Sweden: implications for atmospheric and oceanic forcings of climate, Clim. Dynam., 25, 285-297, 2005.

Tarasov, P. E., Bezrukova, E. V., and Krivonogov, S. K.: Late Glacial and Holocene changes in vegetation cover and climate in southern Siberia derived from a $15 \mathrm{kyr}$ long pollen record from Lake Kotokel, Clim. Past, 5, 285-295, doi:10.5194/cp-5-285-2009, 2009.

Telford, R. and Birks, H.: The secret assumption of transfer functions: problems with spatial autocorrelation in evaluating model performance, Quaternary Sci. Rev., 24, 2173-2179, 2005.

Thomsen, C., Schulz-Bull, D., Petrick, G., and Duinker, J.: Seasonal variability of the long-chain alkenone flux and the effect on the $\mathrm{U}_{k}^{37}$-index in the Norwegian Sea, Org. Geochem., 28, 311-323, 1998.

Thornalley, D., Elderfield, H., and McCave, I.: Holocene oscillations in temperature and salinity of the surface subpolar North Atlantic, Nature, 457, 711-714, 2009.

Viau, A. E. and Gajewski, K.: Reconstructing millennial-scale, regional paleoclimates of Boreal Canada during the Holocene., J. Climate, 22, 316-330, 2009.

Vinther, B., Buchardt, S., Clausen, H., Dahl-Jensen, D., Johnsen, S., Fisher, D., Koerner, R., Raynaud, D., Lipenkov, V., and Andersen, K.: Holocene thinning of the Greenland ice sheet, Nature, 461, 385-388, 2009.

Wanner, H., Beer, J., Bütikofer, J., Crowley, T., Cubasch, U., Flückiger, J., Goosse, H., Grosjean, M., Joos, F., Kaplan, J., Küttel, M., Müller, S., Prentice, I., Solomina, O., Stocker, T., Tarasov, P., Wagner, M., and Widmann, M.: Mid-to Late Holocene climate change: an overview, Quaternary Sci. Rev., 27, 1791-1828, 2008.

Zhao, Y., Braconnot, P., Marti, O., Harrison, S., Hewitt, C., Kitoh, A., Liu, Z., Mikolajewicz, U., Otto-Bliesner, B., and Weber, S.: A multi-model analysis of the role of the ocean on the African and Indian monsoon during the mid-Holocene, Clim. Dynam., 25, 777-800, 2005. 